Western University Scholarship@Western

Earth Sciences Publications

Earth Sciences Department

2018

\title{
Strategies for detecting biological molecules on
} Titan

Catherine Neish

cneish@uwo.ca

Ralph Lorenz

The Johns Hopkins University Applied Physics Laboratory

Elizabeth Turtle

The Johns Hopkins University Applied Physics Laboratory

Jason Barnes

The University of Idaho

Melissa Trainer

Goddard Space Flight Center

See next page for additional authors

Follow this and additional works at: https://ir.lib.uwo.ca/earthpub

Part of the Earth Sciences Commons, and the The Sun and the Solar System Commons

Citation of this paper:

Neish, Catherine; Lorenz, Ralph; Turtle, Elizabeth; Barnes, Jason; Trainer, Melissa; Stiles, Bryan; Kirk, Randolph; Hibbitts, Charles; and Malaska, Michael, "Strategies for detecting biological molecules on Titan" (2018). Earth Sciences Publications. 29.

https://ir.lib.uwo.ca/earthpub/29 
Authors

Catherine Neish, Ralph Lorenz, Elizabeth Turtle, Jason Barnes, Melissa Trainer, Bryan Stiles, Randolph Kirk, Charles Hibbitts, and Michael Malaska 


\section{Strategies for detecting biological molecules on Titan}

3 C.D. Neish ${ }^{1}$, R.D. Lorenz ${ }^{2}$, E. P. Turtle ${ }^{2}$, J.W. Barnes ${ }^{3}$, M. Trainer ${ }^{4}$, B. Stiles ${ }^{5}$, R.

$6{ }^{1}$ Department of Earth Sciences, The University of Western Ontario, London, ON,

$7 \quad$ N6A 5B7, Canada (Phone: 519-661-3188; E-mail: cneish@uwo.ca)

$8 \quad{ }^{2}$ The Johns Hopkins Applied Physics Laboratory, Laurel, MD 20723, USA

$9{ }^{3}$ Department of Physics, University of Idaho, Moscow, ID 83844, USA

$10 \quad{ }^{4}$ NASA Goddard Space Flight Center, Greenbelt, MD 20771, USA

$11{ }^{5}$ Jet Propulsion Laboratory, California Institute of Technology, Pasadena, CA,

1291109, USA

$13{ }^{6}$ United States Geological Survey, Astrogeology Science Center, Flagstaff, AZ,

14 86001, USA 


\section{Abstract}

23 Saturn's moon Titan has all the ingredients needed to produce "life as we know

24 it". When exposed to liquid water, organic molecules analogous to those found on

25 Titan produce a range of biomolecules such as amino acids. Titan thus provides a

26 natural laboratory for studying the products of prebiotic chemistry. In this work,

27 we examine the ideal locales to search for evidence of, or progression towards,

28 life on Titan. We determine that the best sites to identify biological molecules are

29 deposits of impact melt on the floors of large, fresh impact craters, specifically

30 Sinlap, Selk, and Menrva craters. We find that it is not possible to identify

31 biomolecules on Titan through remote sensing, but rather through in-situ

32 measurements capable of identifying a wide range of biological molecules. Given

33 the non-uniformity of impact melt exposures on the floor of a weathered impact

34 crater, the ideal lander would be capable of precision targeting. This would allow

35 it to identify the locations of fresh impact melt deposits, and/or sites where the

36 melt deposits have been exposed through erosion or mass wasting. Determining

37 the extent of prebiotic chemistry within these melt deposits would help us to

38 understand how life could originate on a world very different from Earth.

40 Key words: Titan; Prebiotic chemistry; Solar system exploration; Impact

41 processes; Volcanism 


\section{Introduction}

Saturn's moon Titan has all the ingredients for life as we know it ${ }^{1}$. Titan's

46 dense nitrogen-methane atmosphere supports a rich organic photochemistry

47 (Hörst, 2017). Ultraviolet photons and charged particles dissociate the methane

48 and nitrogen in the atmosphere to produce a suite of carbon, hydrogen, and

49 nitrogen containing products $\left(\mathrm{C}_{\mathrm{x}} \mathrm{H}_{\mathrm{y}} \mathrm{N}_{\mathrm{z}}\right)$, which eventually settle onto the surface.

50 These products have been observed in Titan's atmosphere by the Voyager

51 missions (Hanel et al., 1981; Kunde et al., 1981; Maguire et al., 1981) and in both

52 the atmosphere and on the surface by the Cassini-Huygens mission (Niemann et

53 al., 2005; Lavvas et al., 2008; Janssen et al., 2016).

54 Once on the surface, the products of Titan's photochemistry may react

55 with liquid water in certain circumstances. Titan's surface is on average too cold

56 for liquid water ( $\sim 94 \mathrm{~K}-$ Fulchignoni et al., 2005), but transient liquid water

57 environments may be found in impact melts and cryolavas (Thompson and Sagan,

58 1992; O’Brien et al., 2005; Neish et al., 2006). When organic molecules found on

59 Titan's surface are exposed to liquid water, they quickly incorporate oxygen

60 (Neish et al., 2008; 2009) to produce a range of biomolecules that include amino

61 acids and possibly nucleobases (Neish et al., 2010; Poch et al., 2012; Cleaves et

62 al., 2014). Impact melts and cryolavas of different volumes - and hence, different

\footnotetext{
${ }^{1}$ Here and throughout this paper, we use the term "life as we know it" to refer to carbon-based life that uses water as a solvent.
} 
63 freezing timescales (O’Brien et al., 2005; Davies et al., 2010) - give us a unique

64 window into the extent to which prebiotic chemistry can proceed over different 65 time scales.

66 Thus, Titan provides a natural laboratory for studying the products of 67 prebiotic chemistry. These products provide crucial insight into what may be the 68 first steps towards life in an environment that is rich in carbon and nitrogen, as 69 well as water. It is even possible that life arose on Titan and survived for a short 70 interval before its habitat froze. Alternatively, life may have developed in Titan's 71 subsurface ocean, and evidence of this life could be brought to the surface through 72 geophysical processes such as volcanism (Fortes, 2000). A new exploration 73 strategy is required to collect the results of these natural experiments; such 74 measurements are not possible with the currently available data from the Voyager 75 and Cassini-Huygens missions.

76 Even before Cassini reached the outer solar system, it was recognized 77 that a post-Cassini scientific priority, especially for astrobiology, would be to 78 access surface material for detailed investigation (Chyba et al., 1999; Lorenz, 79 2000). More recently, identifying "Planetary Habitats" was included as one of the 80 three crosscutting themes of the National Research Council's "Visions and 81 Voyages for Planetary Science in the Decade 2013-2022” (Space Studies Board, 82 2012). In addition, Titan is currently listed as one of six potential mission themes 
83 for NASA's next New Frontiers mission ${ }^{2}$. Such a mission could be specifically

84 designed to identify the products of prebiotic chemistry on Titan's surface.

85 In this work, we determine the ideal locales to search for biomolecules

86 on Titan, and suggest mission scenarios to test the hypothesis that the first steps

87 towards life have already occurred there. In this scenario, we would consider a

88 substantial presence of biomolecules (i.e., compounds that are essential to life as

89 we know it) as either a compelling indicator of an advanced prebiotic

90 environment or as a possible sign of extinct (or more speculatively, extant) life.

91

92 2. Geological settings for aqueous chemistry on Titan

93

94 Liquid water is both a crucial source of oxygen and a useful solvent for the

95 generation of biomolecules on Titan's surface. Thus, if we wish to identify

96 molecular indicators of prebiotic chemistry on Titan, we need to determine where

97 liquid water is most likely to have persisted. Although Titan's average surface

98 temperature of $\sim 94 \mathrm{~K}$ precludes the existence of bodies of liquid water over

99 geologic timescales (unless there is an active hotspot - see Schulze-Makuch and

100 Grinspoon, 2005), it does not rule out the presence of water on the surface for

101 short periods of time. We are likely to find transient liquid water environments on

102 the surface of Titan in two distinct geological settings: (1) cryovolcanic lavas and

\footnotetext{
${ }^{2}$ See https://newfrontiers.larc.nasa.gov.
} 
103 (2) melt in impact craters. In addition, Titan's deep interior has a liquid water

104 layer perhaps hundreds of kilometers thick, which may also contain biomolecules

105 (Fortes, 2000; Iess et al., 2012). Samples of this ocean may be transported to the

106 surface through cryovolcanic processes before eventually freezing. Thus, if we

107 wish to find biomolecules on the surface of Titan, we should focus our search in

108 and around cryovolcanoes and impact craters.

109

1102.1 Cryovolcanoes

111

112 On Titan, lavas are generally referred to as cryolavas, since they involve

113 the eruption of substances that are considered volatiles on the surface of Earth

114 (e.g., water, water-ammonia mixtures, etc.). Features suggested to be caused by

115 cryovolcanism were first discovered on the icy satellites during the Voyager

116 missions (e.g., Jankowski and Squyres, 1988; Showman et al., 2004). More recent

117 observations point to the existence of present-day activity on Enceladus (Porco et

118 al., 2006) and Europa (Roth et al., 2014; Sparks et al., 2017).

119 Two conditions must be met for cryovolcanic flows to be present on a

120 surface: liquids must be present in the interior and those liquids must then migrate

121 to the surface. Theoretical models of Titan's formation and evolution predict that

122 a substantial liquid water layer must still exist in its interior, provided a sufficient

123 amount of ammonia is present in the ocean (Tobie et al., 2005). Observations by 
124 the Cassini mission have confirmed the presence of a liquid water subsurface

125 ocean. Measurements of the tidal love number by the Radio Science experiment

126 require that Titan's interior is deformable over its orbital period, consistent with a

127 global ocean at depth (Iess et al., 2012). In addition, the Permittivity, Wave and

128 Altimetry instrument on ESA's Huygens probe detected a electric current in

129 Titan's ionosphere, consistent with a Schumann resonance between two

130 conductive layers. The lower layer was estimated to lie $55-80 \mathrm{~km}$ below the

131 surface, suggestive of a salty, subsurface ocean (Béghin et al., 2012). Other

132 analyses of Titan's overall shape, topography, and gravity field are consistent

133 with an ice shell of this thickness overlying a relatively dense subsurface ocean

134 (Nimmo and Bills, 2010; Mitri et al., 2014)

135 The second requirement for cryovolcanism is for liquid to be transported

136 from the interior to the surface. One plausible way to transport lava is through

137 fluid-filled cracks. Mitri et al. (2008) proposed a model in which ammonia-water

138 pockets are formed through cracking at the base of the ice I shell. As these

139 ammonia-water pockets undergo partial freezing, the ammonia concentration in

140 the pockets would increase, decreasing the negative buoyancy of the ammonia-

141 water mixture. Unlike pure liquid water, a liquid ammonia-water mixture of

142 peritectic composition $\left(\rho=946 \mathrm{~kg} \mathrm{~m}^{-3}\right)$ is near-neutral buoyancy in ice $(\rho=917$

$143 \mathrm{~kg} \mathrm{~m}^{-3}$ ) (Croft et al. 1988). Though these pockets could not easily become

144 buoyant on their own (given the difference in density of $\sim 20-30 \mathrm{~kg} \mathrm{~m}^{-3}$ ), they are 
145 sufficiently close to the neutral buoyancy point that large-scale tectonic stress

146 patterns (tides, non-synchronous rotation, satellite volume changes, solid state

147 convection, or subsurface pressure gradients associated with topography) could

148 enable the ammonia-water to erupt effusively onto the surface. Evidence of such

149 stress patterns are observed on Titan (Cook-Hallet et al., 2015; Liu et al., 2016).

150 Any lava extruded in this way would likely have a peritectic composition near

151 that of pure ammonia dihydrate (33 wt. \% ammonia).

152 We can test the hypothesis that cryolavas have erupted onto Titan's

153 surface by looking for morphological constructs on the surface consistent with

154 volcanism. The Cassini RADAR instrument has imaged approximately two-thirds

155 of the surface of Titan, producing views of the landscape with resolutions as good

156 as $350 \mathrm{~m}$. Although it is difficult to conclusively identify cryovolcanic constructs

157 at these resolutions (Moore and Pappalardo, 2011), several features remain

158 difficult to explain through any other geologic process (Lopes et al., 2013). The

159 most intriguing of these features is Sotra Patera (part of a region formerly known

160 as Sotra Facula). This region includes the deepest pit and some of the highest

161 mountains on Titan, as well as the associated flow-like features of Mohini

162 Fluctus, a $200 \mathrm{~km}$ feature extending from Sotra Patera with a lobate edge (Figure

163 1). If Sotra Patera is indeed a volcanic construct, the lava flows there would be an

164 interesting location for studying the interaction of liquid water with organic

165 molecules on Titan's surface. 
166 However, unless this region represents a persistent hot spot, it is unlikely

167 that the lava will remain liquid long enough for aqueous chemistry to produce 168 complex, biological molecules. (Thus far, no evidence of hot spots has been 169 observed on Titan - Lopes et al., 2013.) Flow lobes tens of meters thick in Mohini 170 Fluctus (Lopes et al., 2013) would likely cool over relatively short timescales: if 171 heat is lost only by conduction, the one-dimensional thermal conduction equation 172 predicts that it should take only one year for a ten-meter-thick flow of water or 173 ammonia dihydrate to completely freeze. Even a $200 \mathrm{~m}$ high cryovolcanic dome 174 that is $90 \mathrm{~km}$ in radius is expected to take only several hundred years to freeze 175 completely (Neish et al., 2006).

176 In addition, if these lavas have a peritectic composition close to that of 177 pure ammonia dihydrate, they would erupt close to a temperature of $176 \mathrm{~K}$. This 178 would significantly affect reaction rates. In a $13 \mathrm{wt} . \%$ ammonia solution at 253

$179 \mathrm{~K}$, reactions between Titan haze analogues and ammonia-water have half-lives of 180 a few days (Neish et al., 2009). According to the Arrhenius equation, a reaction at $181253 \mathrm{~K}$ with an activation energy of $50 \mathrm{~kJ} / \mathrm{mol}$ would take $3 \times 10^{4}$ times longer in a 182 peritectic melt at $176 \mathrm{~K}$. Thus, a reaction that took a few days to complete at the 183 higher temperature would take a few hundred years to complete at the lower 184 temperature. The aqueous chemistry in cryolavas may not have sufficient time or 185 energy to produce more complicated prebiotic molecules.

186 More speculatively, Titan's subsurface ocean may contain biomolecules, 
187 or even simple life forms (Fortes, 2000). Evidence of such biology could be found

188 frozen in the cryovolcanic lavas on the surface of Titan. However, given the

189 uncertain presence of biomolecules in the subsurface ocean, and the challenges

190 inherent in transporting material to the surface, we judge the priority for

191 exploration should focus on another geologic setting where biomolecules are

192 more likely to be present: impact melt deposits.

193

1942.2 Impact craters

195

196 When a comet or asteroid impacts a planet, energy becomes available to 197 melt its surface. Ponds and flows of melted crustal rock are observed in and 198 around impact craters on terrestrial planets (e.g. Hawke and Head, 1977). Models

199 suggest that melt should be produced on icy satellites as well (Pierazzo et al., 200 1997; Artemieva and Lunine 2003; Kraus et al. 2011) and smooth regions at the 201 center of the largest craters on Ganymede have been interpreted to be solidified 202 impact melt (Jones et al., 2003; Bray et al., 2012).

203 Titan's atmosphere is capable of shielding the surface from smaller 204 impactors (Ivanov et al., 1997; Artemieva and Lunine, 2005; Korycansky and 205 Zahnle, 2005), so any projectile that does strike the surface must necessarily be 206 large. Such impactors would melt a substantial amount of Titan's crust. Artemieva 207 and Lunine (2003) conducted three-dimensional hydrodynamical simulations of 
208 impacts into Titan's crust, and found that a $2 \mathrm{~km}$ icy projectile entering the

209 atmosphere at an oblique angle with a velocity of $7 \mathrm{~km} / \mathrm{s}$ would generate $2-5 \%$

210 melt by volume within a transient crater $10-25 \mathrm{~km}$ in diameter. The amount of

211 melt increases with impact energy, so larger craters would contain a larger

212 percentage of melt by volume (Grieve and Cintala, 1992; Cintala and Grieve,

213 1998; Elder et al., 2012).

214 This melt could collect in the lowest parts of the crater, forming a sheet

215 several hundred meters thick. Given the higher density of liquid water compared

216 to the density of ice I, some melt could also drain into fractures in the crater floor

217 before freezing, forming the central pit features seen in craters on many icy

218 satellites (Elder et al., 2012). Using fracture volumes estimated from the gravity

219 anomalies observed over terrestrial impact craters, and assuming flow through

220 plane parallel fractures, Elder et al. (2012) estimated that melt will be retained for

221 Titan craters with diameters greater than $\sim 90 \mathrm{~km}$. However, this is a somewhat

222 idealized situation; in reality, fractures in the brecciated floor of an impact crater

223 are much more sinuous, with variable direction and width. If the fractures have a

224 tortuosity of two, only $\sim 1 / 3$ as much melt would drain (Elder et al., 2012).

225 (Tortuosity is the ratio of the length of the fracture to the depth of the fractured

226 region.) In addition, it is likely that fractures do not have a constant width, which

227 would cause the flow to slow through narrower passages, reducing the total

228 amount of melt volume drained. Since larger craters produce a larger fraction of 
229 melt by volume than smaller craters (Grieve and Cintala, 1992), a reduced

230 drainage efficiency means that melt could also be retained for somewhat smaller

231 impact craters on Titan (larger craters would simply retain more melt than they

232 would if there was more efficient drainage).

233 The organics found on Titan's surface could then react with melt present

234 on the crater floor, in its ejecta blanket, or perhaps mixed with melt that drains

235 into fractures. Artemieva and Lunine (2003) found that a significant fraction

$236(10 \%)$ of Titan's organic surface layer would be only lightly shocked in an

237 impact. As a result, these organic molecules would be only partially altered, 238 providing reactants for any subsequent aqueous chemistry. In impact craters on

239 Earth, impact melt often incorporates large amounts of clastic material from non-

240 melted, but shocked target rocks (Osinski et al., 2017), suggesting there would be

241 efficient mixing between liquid water and organic clasts on Titan. In this way,

242 impact melts could provide "oases" for prebiotic chemistry to occur on Titan's 243 surface.

244 Once melted by the impact, any liquid water generated would begin to 245 cool to the ambient temperature of $\sim 94 \mathrm{~K}$. Thompson and Sagan (1992) were the 246 first to estimate the lifetime of melt pools generated in impacts on Titan. They 247 approximated the melt as a buried sphere of water freezing inward, and found 248 lifetimes of $\sim 10^{4} \mathrm{yr}$ for a $10 \mathrm{~km}$ diameter crater, and $\sim 10^{6} \mathrm{yr}$ for a $100 \mathrm{~km}$ 249 diameter crater. O'Brien et. al. (2005) refined the calculation using a thermal 
250 conduction code, including more realistic geometries (such as sheets of melt

251 several hundreds of meters thick) and the possibility of water-ammonia melt

252 mixtures. With the melt fraction calculated by Artemieva and Lunine (2003), they

253 found somewhat shorter lifetimes of $\sim 10^{2}-10^{3}$ yr for a $15 \mathrm{~km}$ diameter crater, and

$254 \sim 10^{3}-10^{4}$ yr for a $150 \mathrm{~km}$ diameter crater. These lifetimes are considerably longer

255 than those for lava flows tens of meters thick, allowing more time for aqueous

256 chemistry to proceed. (Lifetimes could be reduced if a significant proportion of

257 the melt were to drain into the bottom of the crater, as discussed above.)

258 Impact melts would provide an excellent medium for aqueous chemistry

259 on Titan. In addition to having longer freezing timescales than cryovolcanic

260 flows, they are also likely to be emplaced at much higher temperatures. Melted

261 crustal rock (as opposed to water extruded from depth) is more likely to yield a

262 water-rich composition, with temperatures near the water liquidus $(273 \mathrm{~K})$, not

263 the ammonia-water peritectic $(176 \mathrm{~K})$. Temperatures may even exceed the

264 liquidus initially, given the large amounts of energy available from an impact. For

265 example, there is evidence for super-heating of several hundred Kelvins in impact

266 melts on Earth (Horz, 1965; El Goresy, 1965) and the Moon (Simonds et al.,

267 1976). This could increase the temperature of the melt above the liquidus,

268 accelerating the chemistry occurring in the melt ponds. Reactions between Titan

269 haze analogues and liquid water were roughly 20 times faster at $40^{\circ} \mathrm{C}$ than at $0^{\circ} \mathrm{C}$

270 (Neish et al., 2008). 
271 How many craters are available for such chemistry on Titan? We expect

272 impact cratering to be an important process in the Saturnian system, whose

273 satellites retain thousands of scars from past impacts (e.g., Kirchoff and Schenk,

274 2010). Before Cassini arrived at Saturn, the cratering history on Titan was

275 unknown from direct observations, so estimates of the cratering rate were made

276 by extrapolating the crater distributions observed on other Saturnian satellites, or

277 by predicting impact rates by comet populations. Such estimates suggested that at

278 least several hundred craters larger than $20 \mathrm{~km}$ in diameter should be present on

279 Titan (Zahnle et al. 2003). Now that Cassini RADAR has been able to observe

280 Titan's surface, an extreme paucity of craters is observed. Only 23 certain or

281 nearly certain craters and $\sim 10$ probable craters have been observed on Titan in this

282 size range, with a handful of smaller crater candidates (Wood et al., 2010; Neish

283 and Lorenz, 2012; Neish et al., 2016). This population has crater depths

284 consistently shallower than similarly sized fresh craters on Ganymede, suggestive

285 of extensive modification by erosion and burial (Neish et al., 2013). Although

286 aeolian infilling appears to be the dominant modification process on Titan, fluvial

287 erosion seems to play an important secondary role (Neish et al., 2016). In

288 addition, there is an almost complete absence of craters near Titan's poles, which

289 may be indicative of marine impacts into a former ocean in these regions (Neish

290 and Lorenz, 2014) or an increased rate of fluvial erosion (Neish et al., 2016). 
We therefore judge that the best targets for observing the products of

292 aqueous - and possibly biological - chemistry on Titan are the floors of large,

293 relatively fresh impact craters. Fresh impact craters on Titan are subject to a

294 minimal amount of fluvial incision (which would expose the core of any impact

295 melt sheet), but little to no burial by sand or sediments (Neish et al., 2016). These

296 structures will contain the largest amount of impact melt, and that melt will be

297 easier to access with a spacecraft than the melt in more degraded craters (where it

298 is likely buried under a thick deposit of sediment).

299 To determine the best candidates for such studies, we consider the relative 300 degradation states of all 'certain' or 'nearly certain' craters on Titan with

301 diameters greater than $75 \mathrm{~km}$ (i.e., those craters most likely to retain impact melt).

302 As in Neish et al. (2013), we quantify the degradation state of a crater by 303 considering the relative depth of a Titan crater compared to a fresh, unmodified

304 crater on Ganymede with a similar diameter. The relative depth, $R$, is given by $305 R(\mathrm{D})=1-\mathrm{d}_{\mathrm{t}}(\mathrm{D}) / \mathrm{d}_{\mathrm{g}}(\mathrm{D})$ where $\mathrm{d}_{\mathrm{t}}(\mathrm{D})$ is the depth of a crater with diameter $\mathrm{D}$ on 306 Titan, and $d_{g}(D)$ is the depth of a crater with diameter $\mathrm{D}$ on Ganymede. A relative 307 depth of zero indicates the crater has the same depth as a crater on Ganymede and 308 is thus unmodified by erosion; a relative depth of one indicates the crater is 309 completely flat.

310 There is topography data for seven craters on Titan with $\mathrm{D}>75 \mathrm{~km}$. The 311 relative depths of five of these craters were previously reported in Neish et al. 
312 (2013) and Neish et al. (2015). Topography data for the sixth crater - the $\sim 80 \mathrm{~km}$

313 diameter Selk crater - was obtained during Cassini's T95 pass of Titan on 14

314 October 2013 (Figure 2a). A topographic profile was acquired through the center

315 of the crater using the SARTopo technique (Stiles et al., 2009). We calculated

316 depth, $d=h_{1}-h_{2}$, by taking the difference between the highest point on the crater

317 rim and the lowest point on the crater floor, on both sides of the crater, $d_{1}$ and $d_{2}$

318 (Figure 2b). Systematic errors in height, $\mathrm{dh}_{\mathrm{i}}$, were propagated throughout the

319 analysis. These errors were determined from radar instrument noise and viewing

320 geometry (Stiles et al., 2009). Using this technique, the depth of Selk is $470 \pm 90$ $321 \mathrm{~m}$.

322 Topography data for the seventh crater - the $\sim 140 \mathrm{~km}$ diameter Forseti -

323 was generated from stereo topography produced from overlapping radar images

324 from the T23 and T84 passes of Titan. Unfortunately, the stereo pair only covers

325 the northeast corner of the crater, so our depth estimate is based solely on the rim

326 heights and floor depths observed in this quadrant (Figure 3a). The floor elevation

327 is $-2144 \pm 35 \mathrm{~m}$ and the rim elevation is $-1963 \pm 54 \mathrm{~m}$, for an average depth of

$328180 \pm 60 \mathrm{~m}$. In addition, there is a SARTopo profile through the northeast portion

329 of the crater, generated using data from Cassini's T23 pass (Figure 3b).

330 Unfortunately, there is a data gap present on the crater floor, so we are only able

331 to calculate a minimum crater depth using this data set (Figure 3c). Using the

332 same technique as described for Selk, we found a minimum crater depth of $410 \pm$ 
$33350 \mathrm{~m}$. This differs significantly from the depth derived from the stereo pair.

334 There are several possible reasons for this discrepancy. The crater floor 335 may appear to be level with the crater rim in the stereo pair due to a lack of

336 features on the floor. Identifiable features present in both images are necessary to

337 make stereo measurements. This situation could cause elevations on the crater

338 floor to be interpolated from the nearest rim points, artificially raising points on

339 the crater floor in the stereo data. In addition, impact craters often have large

340 variations in rim height (see, for example, Neish et al. 2017). By only measuring

341 one quadrant of the crater rim, we may not be getting a representative sample of

342 the rim height, thus biasing our result by using a lower than average portion of the

343 crater rim for depth measurements.

344 Updated topography data are also available for the $\sim 100 \mathrm{~km}$ diameter

345 Hano crater. The data were generated from stereo topography produced from

346 overlapping radar images from Cassini's T16 and T84 passes of Titan, and cover

347 more than half of the crater from the southwest quadrant to the northeast quadrant.

348 The result shows a crater with little noticeable topography (Figure 4a). In fact, the

349 average heights in the rim region $(-1500 \pm 170 \mathrm{~m})$ and the average heights in the

350 floor region $(-1510 \pm 140 \mathrm{~m})$ are nearly identical, suggesting that Hano crater is

351 essentially flat $(\mathrm{R} \sim 1)$. The initial depth estimate $(\mathrm{d}=525 \pm 100 \mathrm{~m})$ by Neish et

352 al. (2013) using SARTopo only took into consideration one profile across the

353 southernmost rim of the crater, so it is possible that profile was not representative 
354 of the crater as a whole. An updated SARTopo profile is now available, covering

355 both the northern and southern rim of Hano crater (Figure 4b). Using the same

356 technique as described for Selk, we found a new crater depth of $420 \pm 40 \mathrm{~m}$

357 (Figure 4c). As with Forseti, the stereo and SARTopo values differ considerably

358 for Hano crater, possibly for the same reasons outlined above. However, both of

359 the newly derived depths are lower than the initial estimate from Neish et al.

360 (2013). Thus, Hano appears to be more degraded than originally suggested, which

361 is consistent with its observed morphology in the RADAR data (Wood et al., 362 2010).

363 We summarize the relative depths of the seven craters in Table 1. Of 364 these, only two have relative depths $<0.6$ for all current topography

365 measurements: Sinlap and Selk. We judge these to be the least degraded craters in

366 this size range. In terms of relative depth, Sinlap would be considered the

367 'freshest' crater on Titan, with $\mathrm{R}=0.4 \pm 0.2$. It is difficult to assess the relative

368 depth of the largest crater on Titan, Menrva, since craters in this size range (D >

$369150 \mathrm{~km}$ ) on icy satellites are associated with a sharp reduction in crater depth and

370 anomalous impact morphologies (Schenk, 2002). However, given the large

371 amount of impact melt expected in such a large crater, it remains a high priority

372 target for future exploration. The craters of interest are shown in Figure 5.

373

374 3. Identifying biological molecules on Titan 
376 To identify biological molecules on Titan, it will be necessary to obtain

377 more detailed data than are currently available from past ground- and space-based

378 observations. As we describe below, the remote sensing data sets lack the spatial

379 and spectral resolution to make definitive conclusions about the composition of

380 Titan's surface. Compositional information regarding the potential presence of

381 biological molecules could be obtained from in-situ observations, but only if (a)

382 the associated instrumentation is designed for such a task, and (b) the surface

383 material can be obtained from the targeted regions described in Section 2. In this

384 section, we describe the difficulties in assessing surface composition remotely,

385 and describe possible approaches for in-situ detection of biological molecules.

$387 \quad 3.1$ Detection by remote sensing?

389 To date, Titan has been a focus of a number of spacecraft missions, as well 390 as numerous Earth-based telescopic observations. The collected data have 391 provided global observations of Titan's atmosphere and surface at a range of 392 spatial and spectral resolutions. However, it has remained a difficult challenge to

393 determine the composition of Titan's surface from remote observations (Hörst, 394 2017), for reasons we expand upon below. 
Pioneer 11 was the first spacecraft to encounter Saturn, and acquired the

396 first near range images of Titan in 1979 (Tomasko, 1980). This set the stage for

397 the Voyager missions, which flew by Saturn and Titan in 1980 (Voyager 1) and

3981981 (Voyager 2), respectively (Stone, 1977). The Voyager missions returned

399 important information about Titan's atmospheric chemistry (e.g., Hanel et al.,

400 1981; Kunde et al., 1981; Maguire et al., 1981; Yung et al., 1984), but the

401 cameras on Voyager were unable to resolve any of the fine details of the surface

402 (Richardson et al. 2004). Such images were not obtained until the Cassini-

403 Huygens mission entered orbit around Saturn in 2004. Over the past thirteen years,

404 the Cassini RADAR, VIMS (Visual and Infrared Mapping Spectrometer), and ISS

405 (Imaging Science Subsystem) instruments have provided our first detailed looks

406 at the surface of Titan (Elachi et al., 2005; Barnes et al., 2005; Porco et al., 2005),

407 with the RADAR instrument providing the highest resolution views. However,

408 only $\sim 2 / 3$ of Titan's surface was imaged by the RADAR instrument by the end of

409 the Cassini mission, at resolutions of $350-2000 \mathrm{~m}$. This limited spatial resolution

410 impacts our ability to differentiate surface units on Titan, and hence, determine

411 their differing compositions.

412 In addition to the limited spatial resolution available for Titan, there is

413 limited spectral resolution available for compositional analysis. Due to the

414 presence of Titan's thick nitrogen-methane atmosphere, remote spectroscopic

415 measurements are restricted to a discrete number of atmospheric 'windows', 
416 where scattering and/or absorption are reduced (Lorenz and Mitton, 2002). For

417 example, the VIMS instrument on Cassini has only been able to image the surface

418 of Titan at seven atmospheric windows at wavelengths ranging between 0.94 and

$4195 \mu \mathrm{m}$ (Brown et al., 2004).

420 High spectral resolution is crucial for the remote identification of surface

421 materials. The observation of key spectral features has provided essential

422 information about the composition of many planetary bodies, including the

423 identification of water ice on the Galilean satellites (Pilcher et al., 1972),

424 carbonates on Mars (Ehlmann et al., 2008), and hydroxyl on the Moon (Pieters et

425 al., 2009; Clark, 2009; Sunshine et al., 2009). With only a handful of wavelengths

426 available for surface analysis, similar identifications may be impossible on Titan.

427 The observations are further complicated by residual absorption and scattering 428 within Titan's atmospheric windows. For example, Hayne et al. (2014) found

429 strong atmospheric attenuation in the $2.7 \mu \mathrm{m}$ window compared to the $2.8 \mu \mathrm{m}$ 430 window, resulting in a reversal of the spectral slope expected for water ice.

431 These limitations are present for both orbital and aerial platforms (such as 432 a balloon or aircraft). This is true even though the amount of atmospheric 433 absorption between an aerial platform and the surface is much less than that 434 encountered by an orbiter. For example, the Huygens probe was able to image 435 Titan's surface at the meter scale from an altitude of $10 \mathrm{~km}$ (Tomasko et al., 436 2005), but surface spectra could not be obtained outside of a few specific 
437 spectroscopic windows (Tomasko et al., 2005). This is because at these altitudes, 438 there is little solar illumination for the surface to reflect, since much of the 439 sunlight has been absorbed or scattered by the overlying atmosphere (Tomasko et 440 al., 2005). McDonald et al. (2015) modeled the effect of methane absorption with

441 altitude, and found a slight widening of the spectral windows at altitudes closer to 442 the surface. However, they neglected to include the effects of atmospheric 443 scattering, and thus judge that the broadening they observe is at best an upper 444 limit. As a result, an airplane or balloon would provide little if any improvement 445 in the wavelengths available for spectroscopy over an orbiter. Given these 446 constraints, it would be difficult for a remote spectrometer to identify spectral 447 features associated with common biological molecules on Titan.

448 To test this hypothesis, we obtained reflectance spectra of several 449 molecules of biological interest in the laboratory. These include a pure powdered 450 sample of the amino acid glycine, a pure powdered sample of the amino acid 451 alanine, as well as a reflectance spectrum of a sample of glycine that had been 452 dissolved in water, frozen, and desiccated under vacuum (Figure 6a). We used an 453 ultra-high vacuum system that is able to obtain bidirectional reflectance spectra $454\left(\mathrm{i}=0^{\circ}, \mathrm{e}=30^{\circ}\right)$ using a Bruker FTIR spectrometer. The spectrometer has a typical 455 resolution of $4 \mathrm{~cm}^{-1}$ (or $\sim 10 \mathrm{~nm}$ at $5 \mu \mathrm{m}$, more than two times higher resolution 456 than VIMS), and a wavelength range limited to $\sim 1.8-5.5 \mu \mathrm{m}$ (see Hibbitts and 457 Szanyi, 2007). 
When we compare the brightness of the laboratory spectra in the 2, 2.7,

4592.8 , and $5 \mu \mathrm{m}$ atmospheric windows, we find they are almost indistinguishable

460 from each other. They are also rather featureless, unlike water ice, which shows a

461 prominent absorption band at $2.8 \mu \mathrm{m}$ (Figure 6b). Moreover, given the purity of

462 these samples, the spectra presented here represent the absolute best-case scenario

463 for identifying biological molecules remotely. The concentration of biomolecules

464 in cryolavas and impact melts on Titan is likely to be much lower than the

465 concentrations measured in the laboratory. For example, hydrogen cyanide

466 (HCN), one biomolecule precursor (Ferris et al. 1978), is produced in Titan's

467 atmosphere at a rate of $\sim 1.2 \times 10^{8}$ molecules $\mathrm{cm}^{-}{ }^{2} \mathrm{~s}^{-1}$ (Willacy et al. 2016). If

468 Titan's surface is $\sim 1$ Ga old (the upper limit estimated by Neish and Lorenz,

469 2012), we would expect $\sim 10^{11}$ moles of $\mathrm{HCN}$ per $\mathrm{km}^{2}$. For a $1 \mathrm{~km}^{2}$ region of lava

470 or impact melt, this gives a HCN concentration of 1-10 M (for 10-100 m thick

471 layers of water). If the yield of glycine in such a solution is $\sim 1 \%$ (Ferris et al.

472 1978), we would expect glycine concentrations of only 0.01-0.1 $\mathrm{M}$ in the lava or

473 impact melt. Further, the unique identification of particular molecules within a

474 complex mixture of organics is extremely challenging even with high sensitivity,

475 given multiple overlapping spectral features (see, for example, Clark et al., 2009).

476 Thus, remotely identifying biomolecules on Titan's surface from above or

477 within Titan's atmosphere would be difficult, even with an infrared camera that

478 has finer spatial and spectral resolution and wider spectral range than VIMS. 
$480 \quad 3.2$ Detection by in-situ sampling?

481

Another approach for detecting biological molecules on Titan would be to

483 sample the surface in situ. This approach would require specific measurement 484 strategies. To date, only one spacecraft has acquired in situ information about 485 Titan's surface. In January 2005, the Huygens probe became the first (and only) 486 spacecraft to descend through Titan's atmosphere and land on its surface 487 (Lebreton et al., 2005). It provided detailed information about Titan's atmospheric 488 profile and chemistry (Fulchignoni et al., 2005; Niemann et al., 2005), as well as 489 information about Titan's surface properties (Niemann et al., 2005; Tomasko et 490 al., 2005; Zarnecki et al., 2005). The Huygens probe firmly identified methane 491 and ethane, and tentatively identified cyanogen $\left(\mathrm{C}_{2} \mathrm{~N}_{2}\right)$, benzene $\left(\mathrm{C}_{6} \mathrm{H}_{6}\right)$, and 492 carbon dioxide $\left(\mathrm{CO}_{2}\right)$ on the surface of Titan (Niemann et al. 2010).

493 However, there has been as yet no identification of biological molecules 494 on the surface of Titan, and it is unlikely that such identifications will be possible 495 using the currently available data set. The Huygens probe was designed with 496 essentially no information about Titan's surface and was not guaranteed to survive 497 impact. As a result, it was not capable of precision landing near a site of 498 astrobiological interest, such as an impact crater or cryovolcano. Even if it had 499 landed in such an area, the mass resolution (1 amu) and mass range (1-140 amu) 
500 of the Huygens GCMS (Gas Chromatograph Mass Spectrometer) were not suited

501 to the identification of biological molecules. Oxygenated organic molecules (e.g.,

$502 \mathrm{C}_{\mathrm{v}} \mathrm{H}_{\mathrm{x}} \mathrm{N}_{\mathrm{y}} \mathrm{O}_{\mathrm{z}}$ ) have mass differences much less than 1 amu compared to non-

503 oxygenated molecules of similar molecular weight (e.g., $\mathrm{C}_{\mathrm{v}+1} \mathrm{H}_{\mathrm{x}+4} \mathrm{~N}_{\mathrm{y}}$ ).

504 Distinguishing between these products requires higher resolution mass

505 spectrometers (see Neish et al, 2008; 2009; Hörst et al., 2012; Hörst, 2017) and/or

506 a mechanism for separating different molecules with the same unit mass (Neish et

507 al., 2010; Cleaves et al., 2014). In addition, many amino acids and nucleobases

508 have masses in excess of 140 amu. Glutamine and glutamic acid fall into this

509 mass range, and they represent half of the amino acids identified in one

510 hydrolyzed sample of Titan haze analogues (Neish et al., 2010). Finally, and

511 perhaps most importantly, the surface material sampled by GCMS did not

512 encounter temperatures of more than $\sim 150 \mathrm{~K}$. As a result, no large complex

513 molecules were volatilized and ingested into the instrument (Lorenz et al. 2006).

514 The measurement of complex organics from a surface requires careful sample

515 handling and processing to enable analysis of these molecules without

516 degradation or conversion that obscures the chemical nature of the original

517 material. The Huygens probe was not designed to perform this type of

518 measurement.

519 Identification of biological molecules on Titan would require a spacecraft

520 capable of precision landing, equipped with a payload that is designed to identify 
521 the composition and distribution of the organic molecules present within the

522 water-ice matrix. Existing or proposed spaceflight instrumentation could be used 523 to accomplish the in-situ detection of complex organics and potential 524 biomolecules in the Titan surface environment. Since the deployment of the 525 Huygens probe, two gas-chromatograph mass spectrometers have been flown that 526 exploit a solid sample acquisition and processing capability to pyrolyse samples

527 and measure a wide range of biological molecules (Goesmann et al., 2007; 528 Mahaffy et al., 2012). Both the Rosetta COSAC and Mars Science Laboratory

529 SAM instruments included chiral columns and derivatization agents to allow for 530 the volatilization of key functional groups in biologically interesting molecules, 531 such as amino acids, that would normally degrade or resist transport through the 532 gas chromatography columns (Freissinet et al., 2010). This analysis technique has 533 been demonstrated to successfully detect biomolecules in laboratory-based Titan 534 organic analogs that have undergone hydrolysis (Hörst et al., 2012; Poch et al., 535 2012). The ExoMars MOMA instrument includes an additional capability of 536 laser-desorption mass spectrometry, which may have clear advantages in diverse 537 surface environments and for the measurement of large refractory organic 538 molecules (Siljestrom et al., 2014; Li et al., 2015; Goesmann et al., 2017).

539 Sampling and measurement in organic-laden ices, as proposed here, has 540 recently been discussed in the context of a science feasibility study of a landed 541 Europa mission (Hand et al., 2017). With the goal of searching for signs of life, 
542 the lander's model payload includes an Organic Compositional Analyzer (OCA),

543 baselined to be a GCMS for the detection and identification of molecular

544 biosignatures, similar to those proposed as targets for Titan exploration. The

545 sampling and measurement approach discussed for Europa is highly applicable to

546 the Titan surface; in fact, the much-reduced radiation environment and anticipated

547 high density of organic molecules eases the requirements for chemical

548 characterization on Titan. Additional measurement approaches and sampling

549 implementations have been discussed with respect to the challenges that are

550 unique to cryogenic surfaces (Castillo et al., 2016).

551 In Section 2, we identified the highest priority targets for exploration by in

552 situ sampling systems: the floors of large, relatively unmodified impact craters

553 (specifically, Sinlap, Selk, and Menrva craters). Where, then, would be an ideal

554 place to sample within these craters? Much of Titan is covered in a thick layer of

555 organic molecules (Janssen et al., 2016), so not all impact melt deposits may be

556 accessible on a crater floor or in its ejecta blanket. We need to identify locations

557 where impact melt deposits have been recently exposed through erosion and/or 558 mass wasting.

559 To identify an appropriate sampling site, we consider a relevant terrestrial

560 analogue: Haughton crater in the Canadian Arctic. The 39 Ma Haughton impact

561 structure is a well preserved $23 \mathrm{~km}$ diameter crater in a polar desert, with little to

562 no obscuring vegetation (Osinski et al., 2005; Tornabene et al., 2005). Thus, it is 
563 an excellent analogue for the study of craters on worlds that have experienced

564 moderate amounts of erosion, such as Mars or Titan. We note that the 565 geomorphology of the crater is what makes it a good analogue; the composition of

566 the substrate and chemical weathering experienced by the primarily carbonate

567 rocks at Haughton would be quite different from that experienced by a water-ice-

568 organic bedrock exposed to liquid hydrocarbons on Titan (Lorenz and Lunine,

569 1996). In addition, the periglacial processes that dominate the landscape in the

570 Canadian Arctic would not be found on Titan, where the temperatures are never

571 low enough for liquid hydrocarbons to freeze (Hanley et al., 2017).

572 Mapping in the interior of Haughton has revealed a large deposit of impact

573 melt breccia in the crater floor (the light-toned materials in Figure 7a). Using

574 geologic maps from Osinski et al. (2005), we estimate that this deposit represents

$575 \sim 65 \%$ of the total area of the crater floor within $5 \mathrm{~km}$ of the crater centre (roughly

576 half the radius, $\mathrm{R}$, of the crater), and $\sim 20 \%$ of the crater floor within $10 \mathrm{~km}$ of the

577 crater centre (roughly one crater radius). Thus, a lander would have a high

578 probability of encountering impact melt if it were to land within $1 / 2 \mathrm{R}$ of the crater 579 centre.

580 Notably, this melt deposit has been incised by multiple river channels

581 (Figure 7b), exposing fresh melt surfaces. Additional fluvial erosion and/or mass

582 wasting then brings samples of melt to the flat, smooth, alluvial plain at the

583 bottom of the crater (Figure 7c), where they would be easily accessible by a 
584 lander. The benefit to accessing melt deposits at the bottom of river valleys is that

585 no drilling would be needed to reach an unaltered melt sample. Since liquid

586 hydrocarbons do not react chemically with water ice (Lorenz and Lunine, 1996),

587 even samples exposed to erosion and weathering in the Titan environment would

588 remain relatively pristine. We would also not expect any major alteration due to

589 high-energy electromagnetic radiation and/or charged particles, since ultraviolet

590 radiation and galactic cosmic rays do not penetrate all the way to the surface of

591 Titan (Hörst, 2017). Thus, any biological molecules present would be trapped

592 inside the chemically inert water ice, and so should be accessible when the sample

593 is ingested into a lander. Therefore, if we can identify river valleys on the floors

594 of Sinlap, Selk, and Menrva impact craters, these would be ideal landing sites.

595 The present resolution offered by the Cassini RADAR instrument is 596 insufficient to observe anything but the largest river channels; the Huygens probe

597 saw many more channels near its eventual landing site than are resolved in the 598 corresponding SAR images (e.g., Keller et al., 2008). Still, there is evidence for 599 fluvial erosion in many of Titan's craters; for example, there is evidence for large 600 river channels in the ejecta blankets of both Selk (Soderblom et al., 2010) and

601 Sinlap (Neish et al., 2015). Menrva is also characterized by many large fluvial 602 networks (Lorenz et al., 2008; Wood et al., 2010; Williams et al., 2011), which

603 likely expose impact melt deposits in the channel walls and as riverbed sediments.

604 Imaging from a mobile aerial platform, or perhaps from an orbiter designed to 
605 perform such measurements, could help to identify where the deposits of interest 606 are most accessibly exposed.

607 In this work, we have remained agnostic as to the origin of the biological 608 molecules we seek to find in Titan's impact craters. However, future mission 609 planners may wish to differentiate between those biomolecules formed by abiotic

610 processes and those formed by biotic processes. There are several indicators that

611 may be able to differentiate between biomolecules of biotic origins from those of

612 abiotic origins. For example, one may use isotopic signatures to differentiate

613 between the two; life on Earth preferentially utilizes the lighter isotope of carbon,

$614{ }^{12} \mathrm{C}$, over the heavier isotope, ${ }^{13} \mathrm{C}$ (Cockell, 2015). One may also look for an 615 abundance of molecules with a single chirality; life on Earth uses only the L616 stereoisomer of amino acids, and not their mirror image, the D-stereoisomer 617 (McKay, 2016). Finally, one could consider the broader suite of molecules present 618 in the melt pond; abiotic processes typically produce smooth distributions of 619 organic material, while biologic processes select a highly specific set of molecules 620 (McKay, 2004).

621

\section{4. Conclusions}

623

624 Biomolecules similar to those found on Earth are likely present on Titan. To 625 identify and characterize them would require in-situ measurements of Titan's 
626 surface material, obtained through precision targeting of a lander, equipped with

627 instrumentation capable of measuring a wide range of biological molecules. The

628 ideal landing sites would be the floors of Titan's largest, freshest impact craters,

629 where mass wasting and fluvial erosion expose fresh deposits of impact melt for

630 sampling. Impact craters are preferred over cryovolcanoes for a number of

631 reasons, chief among them the temperature of the aqueous medium; higher

632 temperatures at impact craters will increase reaction rates exponentially,

633 increasing the likelihood of forming complex biomolecules. Determining the

634 extent of prebiotic chemistry within these melt deposits would help us to

635 understand how life could originate on a world very different from Earth, and

636 shed light on prebiotic synthesis more generally.

\section{Acknowledgments}

639

640 We wish to acknowledge the Cassini RADAR team for acquiring and processing

641 the data presented here. We also wish to thank two anonymous reviewers whose

642 comments helped to improve the manuscript. The research was supported in part

643 by the Cassini-Huygens mission, a cooperative endeavor of NASA, ESA, and ASI

644 managed by JPL/Caltech under a contract with NASA. C. N. also thanks the

645 Canadian Space Agency and the Natural Sciences and Engineering Research

646 Council of Canada for funds that supported field work at the Haughton impact 
647 structure. R. L. acknowledges the support of NASA PDART grant 648 NNX15AM23G.

649

650 Author Disclosure Statement

651

652 No competing financial interests exist.

653

654 


\section{References}

656

657 Artemieva, N., and Lunine, J. (2003). Cratering on Titan: impact melt, ejecta, and 658 the fate of surface organics. Icarus 164:471-480.

659

660 Artemieva, N., and Lunine, J. I. (2005). Numerical calculations of the longevity 661 of impact oases on Titan. Icarus 173:243-253.

662

663 Barnes, J. W., Brown, R. H., Turtle, E. P., McEwen, A. S., et al. (2005). A 5-

664 micron-bright spot on Titan: Evidence for surface diversity. Science 310:92-95.

665

666 Barnes, J. W., Brown, R. H., Soderblom, L., Buratti, B. J., Sotin, C., Rodriguez,

667 S., Baines, K. H., Clark, R., and Nicholson, P. (2007). Global-scale surface 668 spectral variations on Titan seen from Cassini/VIMS. Icarus 186:242-258.

669

670 Barnes, J. W., Lemke, L., Foch, R., McKay, C. P., Beyer, R. A., Radebaugh, J., et 671 al. (2012). AVIATR-Aerial Vehicle for In-situ and Airborne Titan 672 Reconnaissance. A Titan airplane mission concept. Experimental Astronomy $673 \quad 33: 55-127$.

674

675 Béghin, C. B., Randriamboarison, O., Hamelin, M., Karkoschka, E., Sotin, C., 
676 Whitten, R. C., et al. (2012). Analytic theory of Titan's Schumann resonance:

677 Constraints on ionospheric conductivity and buried water ocean. Icarus $678 \quad 218: 1028-1042$.

680 Bray, V. J., Schenk, P. M., Melosh, H. J., Morgan, J. V., and Collins, G. S. 681 (2012). Ganymede crater dimensions: Implications for central peak and central pit 682 formation and development. Icarus 217:115-129.

683

684 Brown, R. H., Baines, K. H., Bellucci, G., Bibring, J. P., Buratti, B. J., 685 Capaccioni, F., et al. (2004). The Cassini visual and infrared mapping 686 spectrometer (VIMS) investigation. Space Science Reviews 115:111-168.

687

688 Castillo, J. C., Y. Bar-Cohen, S. Vance, M. Choukroun, H. J. Lee, X. Bao, M. 689 Badescu, S. Sherrit, M. G. Trainer, and S. A. Getty (2016). Sample Handling and 690 Instruments for the In Situ Exploration of Ice-Rich Planets. In: Low Temperature 691 Materials and Mechanisms, edited by Y. Bar-Cohen, CRC Press, Boca Raton, FL, 692 pp. 229-270.

693

694 Chyba, C. et al. (1999). Europa and Titan: Preliminary Recommendations of the 695 Campaign Science Working Group on Prebiotic Chemistry in the Outer Solar 696 System. In: 30th Lunar and Planetary Science Conference Abstracts, Houston, 
697 Texas, USA.

698

699 Cintala, M. J., and Grieve, R. A. F. (1998). Scaling impact-melt and crater

700 dimensions: Implications for the lunar cratering record. Meteoritics \& Planetary

701 Science 33:889-912.

702

703 Clark, R. N. (2009). Detection of Adsorbed Water and Hydroxyl on the Moon.

704 Science 326:562-564.

705

706 Clark, R.N., Curchin, J.M., Hoefen, T.M., and Swayze, G.A. (2009) Reflectance

707 spectroscopy of organic compounds: 1. Alkanes. Journal of Geophysical $708 \quad$ Research 114:E03001.

709

710 Cleaves, H. J., Neish, C., Callahan, M. P., Parker, E., Fernández, F. M., and

711 Dworkin, J. P. (2014). Amino acids generated from hydrated Titan tholins:

712 Comparison with Miller-Urey electric discharge products. Icarus 237:182-189.

713

714 Cockell, C.S. (2015). Astrobiology: Understanding life in the universe. John

715 Wiley \& Sons, Ltd., Sussex, UK, 449 pp.

716 
717 Cook-Hallett, C., J. W. Barnes, S. A. Kattenhorn, T. Hurford, J. Radebaugh, B.

718 Stiles, and M. Beuthe (2015). Global contraction/expansion and polar lithospheric

719 thinning on Titan from patterns of tectonism. Journal of Geophysical Research-

720 Planets 120:1220-1236.

721

722 Coustenis, A., Atreya, S. K., Balint, T., Brown, R. H., Dougherty, M. K., Ferri, F.,

723 et al. (2008). TandEM: Titan and Enceladus mission. Experimental Astronomy

724 23:893-946.

725

726 Croft, S., Lunine, J., and Kargel, J. (1988). Equation of state of ammonia-water

727 liquid: Derivation and planetological applications. Icarus 73:279-293.

728

729 Davies, A.G., Sotin, C., Matson, D.L., Castillo-Rogez, J., Johnson, T.V.,

730 Choukroun, M., and Baines, K.H. (2010). Atmospheric control of the cooling rate

731 of impact melts and cryolavas on Titan's surface. Icarus 208:887-895.

732

733 Ehlmann, B. L., Mustard, J. F., Murchie, S. L., Poulet, F., Bishop, J. L., Brown,

734 A. J., et al. (2008). Orbital Identification of Carbonate-Bearing Rocks on Mars.

735 Science 322:1828-1832.

736 
737 El Goresy, A. (1965). Baddeleyite and its significance in impact glasses. Journal 738 of Geophysical Research 70:3453-3456.

739

740 Elachi, C., et al. (2005). Cassini Radar Views the Surface of Titan. Science $741 \quad 308: 970-974$.

742

743 Elder, C. M., Bray, V. J., and Melosh, H. J. (2012). The theoretical plausibility of 744 central pit crater formation via melt drainage. Icarus 221:831-843.

746 Ferris, J., Joshi, P., Edelson, E., and Lawless, J. (1978). HCN: a plausible source 747 of purines, pyrimidines and amino acids on the primitive Earth. Journal of 748 Molecular Evolution 11:293-311.

749

750 Fortes, A. (2000). Exobiological Implications of a Possible Ammonia-Water 751 Ocean inside Titan. Icarus 146:444-452.

752

753 Freissinet, C., A. Buch, R. Sternberg, C. Szopa, C. Geffroy-Rodier, C. Jelinek, 754 and M. Stambouli (2010). Search for evidence of life in space: Analysis of 755 enantiomeric organic molecules by $\mathrm{N}, \mathrm{N}$-dimethylformamide dimethylacetal 756 derivative dependant Gas Chromatography-Mass Spectrometry. Journal of 757 Chromatography A 1217:731-740. 
759 Fulchignoni, M., Ferri, F., Angrilli, F., Ball, A. J., Bar-Nun, A., Barucci, M. A., et

760 al. (2005). In situ measurements of the physical characteristics of Titan's

761 environment. Nature 438:785-791.

762

763 Goesmann, F., Rosenbauer, H., Roll, R., Szopa, C., Raulin, F., Sternberg, R., et al.

764 (2007). COSAC, The Cometary Sampling and Composition Experiment on

765 Philae. Space Science Reviews 128:257-280.

766

767 Goesmann, F., et al. (2017), The Mars Organic Molecule Analyzer (MOMA)

768 Instrument: Characterization of Organic Material in Martian Sediments, 769 Astrobiology 17:655-685.

771 Grieve, R.A.F., and Cintala, M.J. (1992). An analysis of differential impact melt-

772 crater scaling and implications for the terrestrial impact record. Meteoritics \& 773 Planetary Science 27:526-538.

774

775 Hand, K.P., Murray, A.E., Garvin, J.B., Brinckerhoff, W.B., Christner, B.C,

776 Edgett, K.S, Ehlmann, B.L., German, C.R., Hayes, A.G., Hoehler, T.M.,

777 Horst, S.M., Lunine, J.I., Nealson, K.H., Paranicas, C., Schmidt, B.E., Smith, 778 D.E., Rhoden, A.R., Russell, M.J., Templeton, A.S., Willis, P.A., Yingst, 
779 R.A., Phillips, C.B, Cable, M.L., Craft., K.L., Hofmann, A.E., Nordheim,

780 T.A., Pappalardo, R.P., and the Project Engineering Team (2017). Report of

781 the Europa Lander Science Definition Team. Posted February, 2017.

782

783 Hanel R, Conrath B, Flasar FM, Kunde V, Maguire W, Pearl J, Pirraglia J,

784 Samuelson R, Herath L, Allison M, Cruikshank D, Gautier D, Gierasch P, Horn

785 L, Koppany R, Ponnamperuma C (1981). Infrared observations of the saturnian

786 system from voyager 1. Science 212:192-200.

787

788 Hanley, J., Pearce, L., Thompson, G., Grundy, W., Roe, H., Lindberg, G.,

789 Dustrud, S., Trilling, D., and Tegler, S. (2017). Methane, Ethane, and Nitrogen

790 Stability on Titan. In: 48th Lunar and Planetary Science Conference Abstracts,

791 The Woodlands, Texas, USA.

792

793 Hawke, B.R., and Head, J.W. (1977). Impact melt in lunar crater interiors. In:

794 Impact and explosion cratering, edited by D.J. Roddy, R.O. Pepin, and R.B.

795 Merrill, Pergamon Press, New York, NY, pp. 815.

796

797 Hayne, P. O., McCord, T. B., and Sotin, C. (2014). Titan's surface composition

798 and atmospheric transmission with solar occultation measurements by Cassini

799 VIMS. Icarus 243:158-172. 
801 Hibbitts, C. A., and Szanyi, J. (2007). Physisorption of CO2 on nonice materials

802 relevant to icy satellites. Icarus 191:371-380.

803

804 Hörst, S. M., Yelle, R. V., Buch, A., Carrasco, N., Cernogora, G., Dutuit, O., 805 Quirico, E., Sciamma-O’Brien, E., Smith, M. A., Somogyi, A., Szopa, C., 806 Thissen, R., and Vuitton, V. (2012). Formation of Amino Acids and Nucleotide

807 Bases in a Titan Atmosphere Simulation Experiment. Astrobiology 12:809-817.

808

809 Hörst, S. M. (2017). Titan's atmosphere and climate. Journal of Geophysical 810 Research-Planets 122:432-482.

811

812 Hörz F. (1965). Untersuchungen an Riesgläsern, Beiträge zur Mineralogie und 813 Petrographie 11:621-661.

814

815 Iess, L., Jacobson, R. A., Ducci, M., Stevenson, D. J., Lunine, J. I., Armstrong, J. 816 W., et al. (2012). The Tides of Titan. Science 337:457-459.

818 Ivanov, B. A., Basilevsky, A. T., and Neukum, G. (1997). Atmospheric entry of 819 large meteoroids: implication to Titan. Planetary and Space Science 45:9938201007. 
822 Jankowski, D., and Squyres, S. (1988). Solid-State Ice Volcanism on the Satellites 823 of Uranus. Science 241:1322-1325.

824

825 Janssen, M. A., Le Gall, A., Lopes, R. M., Lorenz, R. D., Malaska, M. J., Hayes, 826 A. G., et al. (2016). Titan's surface at 2.18-cm wavelength imaged by the Cassini

827 RADAR radiometer: Results and interpretations through the first ten years of 828 observation. Icarus 270:443-459.

829

830 Jones, K. B., Head, J. W., III, Pappalardo, R. T., and Moore, J. M. (2003).

831 Morphology and origin of palimpsests on Ganymede based on Galileo 832 observations. Icarus 164:197-212.

833

834 Keller, H. U., Grieger, B., Küppers, M., Schröder, S. E., Skorov, Y. V., and 835 Tomasko, M. G. (2008). The properties of Titan's surface at the Huygens landing 836 site from DISR observations. Planetary and Space Science 56:728-752.

838 Kirchoff, M.R. and Schenk, P. (2010). Impact cratering records of the mid-sized, 839 icy saturnian satellites. Icarus 206:485-497. 840

841 Korycansky, D. G., and Zahnle, K. J. (2005). Modeling crater populations on 
842 Venus and Titan. Planetary and Space Science 53:695-710.

843

844 Kraus, R. G., Senft, L. E., and Stewart, S. T. (2011). Impacts onto H2O ice:

845 Scaling laws for melting, vaporization, excavation, and final crater size. Icarus $846 \quad 214: 724-738$.

847

848 Kunde, V. G., Aikin, A. C., Hanel, R. A., and Jennings, D. E. (1981). C4H2, 849 HC3N and C2N2 in Titan's atmosphere. Nature 292:686-688.

850

851 Lavvas, P. P., Coustenis, A., and Vardavas, I. M. (2008). Coupling 852 photochemistry with haze formation in Titan's atmosphere, Part II: Results and 853 validation with Cassini/Huygens data. Planetary and Space Science 56:67-99.

855 Lebreton, J.-P., Witasse, O., Sollazzo, C., Blancquaert, T., Couzin, P., Schipper, 856 A.-M., et al. (2005). An overview of the descent and landing of the Huygens 857 probe on Titan. Nature 438:758-764.

858

859 Li, X., R. M. Danell, W. B. Brinckerhoff, V. T. Pinnick, F. van Amerom, R. D.

860 Arevalo, S. A. Getty, P. R. Mahaffy, H. Steininger, and F. Goesmann (2015).

861 Detection of Trace Organics in Mars Analog Samples Containing Perchlorate by 862 Laser Desorption/Ionization Mass Spectrometry. Astrobiology 15:104-110. 
864 Liu, Z.Y.C., Radebaugh, J., Christiansen, E.H., Harris, R.A., Neish, C.D., Kirk,

865 R.L. and Lorenz, R.D. (2016) The tectonics of Titan: Global structural mapping 866 from Cassini RADAR. Icarus 270:14-29.

867

868 Lopes, R. M. C., Kirk, R. L., Mitchell, K. L., Legall, A., Barnes, J. W., Hayes, A., 869 et al. (2013). Cryovolcanism on Titan: New results from Cassini RADAR and 870 VIMS. Journal of Geophysical Research-Planets 118:416-435.

871

872 Lorenz, R.D. (2000) Post-Cassini Exploration of Titan: Science Rationale and

873 Mission Concepts. Journal of the British Interplanetary Society 53:218-234.

874

875 Lorenz, R., and Mitton, J. (2002). Lifting Titan's Veil. Cambridge University 876 Press, Cambridge, UK, 260 pp.

878 Lorenz, R. D., and Lunine, J. I. (1996). Erosion on Titan: Past and present. Icarus 879 122:79-91.

880

881 Lorenz, R. D., Niemann, H., Harpold, D., and Zarnecki, J. (2006). Titan's Damp

882 Ground: Constraints on Titan Surface Thermal Properties from the Temperature 883 Evolution of the Huygens GCMS inlet. Meteoritics and Planetary Science 
886 Lorenz, R. D., Lopes, R. M., Paganelli, F., Lunine, J. I., Kirk, R. L., Mitchell, K.

887 L., et al. (2008). Fluvial channels on Titan: Initial Cassini RADAR observations. $888 \quad$ Planetary and Space Science 56:1132-1144.

890 Lorenz, R. D., Stofan, E., Lunine, J. I., Zarnecki, J. C., Harri, A. M., Karkoschka, 891 E., et al. (2012). MP3 - A meteorology and physical properties package to explore 892 air-sea interaction on Titan. In: 43rd Lunar and Planetary Science Conference 893 Abstracts, Houston, Texas, USA.

895 Maguire, W. C., Hanel, R. A., Jennings, D. E., and Kunde, V. G. (1981). C3H8 896 and C3H4 in Titan's atmosphere. Nature 292:683-686.

898 Mahaffy, P. R., Webster, C. R., Cabane, M., Conrad, P. G., Coll, P., Atreya, S. K., 899 et al. (2012). The Sample Analysis at Mars Investigation and Instrument Suite. $900 \quad$ Space Science Reviews 170:401-478.

901

902 McDonald, G.D., Corlies, P., Wray, J.J., Horst, S.M., Hofgartner, J.D., Liuzzo, 903 L.R., Buffo, J., and Hayes, A. G. (2015). Altitude-dependence of Titan's methane 904 transmission windows: Informing future missions. In: $46^{\text {th }}$ Lunar and Planetary 
905 Science Conference Abstracts, The Woodlands, Texas, USA.

906

907 McKay, C. P. (2004). What Is Life-and How Do We Search for It in Other

908 Worlds? PLoS Biology, 2:e302-4.

909

910 McKay, C. P. (2016). Titan as the Abode of Life. Life 6:8.

911

912 Mitri, G., Showman, A., Lunine, J., and Lopes, R. (2008). Resurfacing of Titan by

913 ammonia-water cryomagma. Icarus 196:216-224.

914

915 Mitri, G., Meriggiola, R., Hayes, A., Lefèvre, A., Tobie, G., Genova, A., et al.

916 (2014). Shape, topography, gravity anomalies and tidal deformation of Titan.

917 Icarus 236:169-177.

918

919 Moore, J. M., and Pappalardo, R. T. (2011). Titan: An exogenic world? Icarus $920 \quad 212: 790-806$.

921

922 Neish, C. D., and Lorenz, R. D. (2012). Titan's global crater population A new 923 assessment. Planetary and Space Science 60:26-33.

924

925 Neish, C. D., and Lorenz, R. D. (2014). Elevation distribution of Titan's craters 
926 suggests extensive wetlands. Icarus 228:27-34.

927

928 Neish, C. D., Lorenz, R. D., O'Brien, D. P., and the Cassini RADAR Team.

929 (2006). The potential for prebiotic chemistry in the possible cryovolcanic dome

930 Ganesa Macula on Titan. International Journal of Astrobiology 5:57-65.

931

932 Neish, C. D., Somogyi, Á., Imanaka, H., Lunine, J. I., and Smith, M. A. (2008).

933 Rate Measurements of the Hydrolysis of Complex Organic Macromolecules in

934 Cold Aqueous Solutions: Implications for Prebiotic Chemistry on the Early Earth 935 and Titan. Astrobiology 8:273-287.

936

937 Neish, C. D., Somogyi, Á., Lunine, J. I., and Smith, M. A. (2009). Low 938 temperature hydrolysis of laboratory tholins in ammonia-water solutions:

939 Implications for prebiotic chemistry on Titan. Icarus 201:412-421.

940

941 Neish, C. D., Somogyi, Á., and Smith, M. A. (2010). Titan's Primordial Soup:

942 Formation of Amino Acids via Low-Temperature Hydrolysis of Tholins.

943 Astrobiology 10:337-347.

944

945 Neish, C. D., Kirk, R. L., Lorenz, R. D., Bray, V. J., Schenk, P., Stiles, B. W., et

946 al. (2013). Crater topography on Titan: Implications for landscape evolution. 
949 Neish, C. D., Barnes, J. W., Sotin, C., MacKenzie, S., Soderblom, J. M., Le

950 Mouélic, S., et al. (2015). Spectral properties of Titan's impact craters imply

951 chemical weathering of its surface. Geophysical Research Letters 42:3746-3754.

952

953 Neish, C. D., Molaro, J. L., Lora, J. M., Howard, A. D., Kirk, R. L., Schenk, P., et

954 al. (2016). Fluvial erosion as a mechanism for crater modification on Titan. Icarus $955 \quad 270: 114-129$.

956

957 Neish, C. D., Herrick, R. R., Zanetti, M., and Smith, D. (2017). The role of pre958 impact topography in impact melt emplacement on terrestrial planets. Icarus $959 \quad 297: 240-251$.

960

961 Niemann, H. B., Atreya, S. K., Bauer, S. J., Carignan, G. R., Demick, J. E., Frost,

962 R. L., et al. (2005). The abundances of constituents of Titan's atmosphere from 963 the GCMS instrument on the Huygens probe. Nature 438:779-784.

964

965 Niemann, H. B., Atreya, S. K., Demick, J. E., Gautier, D., Haberman, J. A., 966 Harpold, D. N., Kasprzak, W. T., Lunine, J. I., Owen, T. C., and Raulin, F. 967 (2010). Composition of Titan's lower atmosphere and simple surface volatiles as 
968 measured by the Cassini-Huygens probe gas chromatograph mass spectrometer

969 experiment. Journal of Geophysical Research 115:E12006.

970

971 Nimmo, F., and Bills, B. G. (2010). Shell thickness variations and the long-

972 wavelength topography of Titan. Icarus 208:896-904.

973

974 O'Brien, D. P., Lorenz, R. D., and Lunine, J. I. (2005). Numerical calculations of 975 the longevity of impact oases on Titan. Icarus 173:243-253.

976

977 Osinski, G. R., Lee, P., Parnell, J., and Spray, J. G. (2005). A case study of 978 impact-induced hydrothermal activity: The Haughton impact structure, Devon

979 Island, Canadian High Arctic. Meteoritics \& And Planetary Science 40:18599801877.

981

982 Osinski, G.R., Grieve, R.A.F., Bleacher, J.E., Pilles, E.A., and Tornabene, L.L. 983 (2017) Igneous rocks formed by hypervelocity impact. Journal of Volcanological 984 and Geothermal Research submitted.

985

986 Pierazzo, E., Vickery, A. M., and Melosh, H. J. (1997). A Reevaluation of Impact 987 Melt Production. Icarus 127:408-423.

988 
989 Pieters, C. M., Goswami, J. N., Clark, R. N., Annadurai, M., Boardman, J., 990 Buratti, B., et al. (2009). Character and Spatial Distribution of OH/H2O on the 991 Surface of the Moon Seen by M3 on Chandrayaan-1. Science 326:568-572.

992

993 Pilcher, C. B., Ridgway, S. T., and McCord, T. B. (1972). Galilean Satellites:

994 Identification of Water Frost. Science 178:1087-1089.

995

996 Poch, O., Coll, P., Buch, A., Ramírez, S. I., and Raulin, F. (2012). Production 997 yields of organics of astrobiological interest from H2O-NH3 hydrolysis of Titan's 998 tholins. Planetary and Space Science 61:114-123.

999

1000 Porco, C. C., Baker, E., Barbara, J., Beurle, K., Brahic, A., Burns, J. A., et al. 1001 (2005). Imaging of Titan from the Cassini spacecraft. Nature 434:159-168.

1002

1003 Porco, C. C., Helfenstein, P., Thomas, P. C., Ingersoll, A. P., Wisdom, J., West, 1004 R., et al. (2006). Cassini Observes the Active South Pole of Enceladus. Science $1005311: 1393-1401$.

1006

1007 Richardson, J., Lorenz, R. D., and McEwen, A. (2004). Titan's surface and 1008 rotation: new results from Voyager 1 images. Icarus 170:113-124. 
1010 Roth, L., Retherford, K. D., Saur, J., Strobel, D. F., Feldman, P. D., McGrath, M.

1011 A., and Nimmo, F. (2014). Orbital apocenter is not a sufficient condition for 1012 HST/STIS detection of Europa's water vapor aurora. Proceedings of the National 1013 Academy of Sciences 111:E5123-E5132.

1014

1015 Schenk, P. M. (2002). Thickness constraints on the icy shells of the galilean 1016 satellites from a comparison of crater shapes. Nature 417:419-421.

1017

1018 Schulze-Makuch, D., and Grinspoon, D. (2005). Biologically enhanced energy 1019 and carbon cycling on Titan? Astrobiology 5:560-567.

1020

1021 Showman, A. P., Mosqueira, I., and Head, J. W., III. (2004). On the resurfacing of 1022 Ganymede by liquid-water volcanism. Icarus 172:625-640.

1023

1024 Siljestrom, S., C. Freissinet, F. Goesmann, H. Steininger, W. Goetz, A. Steele, H. 1025 Amundsen, and the AMASE11 Team (2014). Comparison of Prototype and 1026 Laboratory Experiments on MOMA GCMS: Results from the AMASE11 1027 Campaign. Astrobiology 14:780-797.

1028

1029 Simonds, C.H., Warner, J.L., and Phinney, W.C. (1976). Thermal regimes in 1030 cratered terrain with emphasis on the role of impact melt. American Mineralogist 
$1031 \quad 61: 569-577$.

1032

1033 Soderblom, J. M., Brown, R. H., Soderblom, L. A., Barnes, J. W., Jaumann, R.,

1034 Le Mouélic, S., et al. (2010). Geology of the Selk crater region on Titan from

1035 Cassini VIMS observations. Icarus 208:905-912.

1036

1037 Space Studies Board (2012). Vision and Voyages for Planetary Science in the 1038 Decade 2013-2022. National Academies Press. Available online at 1039 http://solarsystem.nasa.gov/docs/Vision_and_Voyages-FINAL.pdf.

1040

1041 Sparks, W.B., Schmidt, B.E., McGrath, M.A., Hand, K.P., Spencer, J.R., Cracraft, 1042 M., and Deustua, S.E. (2017). Active Cryovolcanism on Europa? Astrophysical 1043 Journal Letters 839:L18.

1044

1045 Stiles, B. W., Hensley, S., Gim, Y., Bates, D. M., Kirk, R. L., Hayes, A., et al. 1046 (2009). Determining Titan surface topography from Cassini SAR data. Icarus $1047 \quad 202: 584-598$.

1048

1049 Stofan, E., Lorenz, R. D., Lunine, J. I., Bierhaus, E. B., Clark, B., Mahaffy, P.R., 1050 Ravine, M. (2013). TiME-The Titan Mare Explorer. In: Proceedings of IEEE 1051 Aerospace Conference, Big Sky, MT, March 2013, paper \#2434. 
1053 Sunshine, J. M., Farnham, T. L., Feaga, L. M., Groussin, O., Merlin, F., Milliken,

1054 R. E., and A'Hearn, M. F. (2009). Temporal and Spatial Variability of Lunar

1055 Hydration As Observed by the Deep Impact Spacecraft. Science 326:565-568.

1056

1057 Thompson, W.R. and Sagan, C. (1992). Organic chemistry on Titan: surface 1058 interactions. In: Proceedings of the Symposium on Titan, 9-12 September 1991, 1059 Toulouse, France. ESA SP-338, pp. 167-176.

1060

1061 Tobie, G., Grasset, O., Lunine, J. I., Mocquet, A., and Sotin, C. (2005). Titan's

1062 internal structure inferred from a coupled thermal-orbital model. Icarus 175:4961063502.

1064

1065 Tomasko, M. G. (1980). Preliminary results of polarimetry and photometry of 1066 Titan at large phase angles from Pioneer 11. Journal of Geophysical Research:

1067 Space Physics 85:5937-5942.

1068

1069 Tomasko, M. G., Archinal, B., Becker, T., Bézard, B., Bushroe, M., Combes, M., 1070 et al. (2005). Rain, winds and haze during the Huygens probe's descent to Titan's 1071 surface. Nature 438:765-778.

1072 
1073 Tornabene, L. L., Moersch, J. E., Osinski, G. R., Lee, P., and Wright, S. P.

1074 (2005). Spaceborne visible and thermal infrared lithologic mapping of impact-

1075 exposed subsurface lithologies at the Haughton impact structure, Devon Island,

1076 Canadian High Arctic: Applications to Mars. Meteoritics \& Planetary Science $1077 \quad 40: 1835-1858$.

1078

1079 Trainer, M. G., Mahaffy, P. R., Stofan, E. R., Lunine, J. I., and Lorenz, R. D.

1080 (2012). Measuring the Composition of a Cryogenic Sea. International Workshop 1081 on Instrumentation for Planetary Missions 1683:1033.

1082

1083 Willacy, K., Allen, M. and Yung, Y. (2016). A new astrobiological model of the 1084 atmosphere of Titan. The Astrophysical Journal 829:79.

1085

1086 Williams, D.A., Radebaugh, J., Lopes, R.M.C., and Stofan, E. (2011)

1087 Geomorphologic mapping of the Menrva region of Titan using Cassini RADAR 1088 data. Icarus 212:744-750.

1089

1090 Wood, C. A., Lorenz, R., Kirk, R., Lopes, R., Mitchell, K., and Stofan, E. (2010).

1091 Impact craters on Titan. Icarus 206:334-344.

1092

1093 Yung, Y. L., Allen, M., and Pinto, J. P. (1984). Photochemistry of the atmosphere 
1094 of Titan - Comparison between model and observations. Astrophysical Journal

1095 Supplement Series 55:465-506.

1096

1097 Zahnle, K., Schenk, P., Levison, H., and Dones, L. (2003). Cratering rates in the

1098 outer Solar System. Icarus 163:263-289.

1099

1100 Zarnecki, J. C., Leese, M. R., Hathi, B., Ball, A. J., Hagermann, A., Towner, M.

1101 C., et al. (2005). A soft solid surface on Titan as revealed by the Huygens Surface

1102 Science Package. Nature 438:792-795.

1103 


\section{Tables}

1105

1106 Table 1: Relative depths for seven 'certain' or 'nearly certain' craters on Titan 1107 with $\mathrm{D}>75 \mathrm{~km}$.

\begin{tabular}{|l|l|l|l|l|l|l|}
\hline Crater & Diameter, & Depth, d (m) & Technique & Relative depth, $\mathbf{R}^{\mathbf{a}}$ & Relative depth, $\mathbf{R}^{\mathbf{c}}$ & Source of Depth $^{\text {Measurement }}$ \\
\hline Soi & $78 \pm 2$ & $240 \pm 120$ & Stereo & $0.78 \pm 0.11$ & $0.76 \pm 0.12$ & Neish et al. (2015) \\
\hline Selk & $79 \pm 7$ & $470 \pm 90$ & SARTopo & $0.58 \pm 0.08$ & $0.53 \pm 0.09$ & This paper \\
\hline Sinlap & $82 \pm 2$ & $640(+160 /-150)$ & SARTopo & $0.43(+0.14 /-0.13)$ & $0.36(+0.16 /-0.15)$ & Neish et al. (2013) \\
\hline Hano & $100 \pm 5$ & $420 \pm 40$ & SARTopo & $0.65 \pm 0.03$ & $0.56 \pm 0.04$ & This paper \\
\hline & & $\sim 0$ & Stereo & $\sim 1$ & $\sim 1$ & This paper \\
\hline Afekan & $115 \pm 5$ & $455(+175 /-180)$ & SARTopo & $0.62(+0.15 /-0.15)^{b}$ & $0.52(+0.19 /-0.19)$ & Neish et al. (2013) \\
\hline Forseti & $140 \pm 10$ & $180 \pm 60$ & Stereo & $0.85 \pm 0.05^{\mathrm{b}}$ & $0.80 \pm 0.07$ & This paper \\
\hline & & $>410 \pm 50$ & SARTopo & $<0.66 \pm 0.04^{\mathrm{b}}$ & $<0.55 \pm 0.06$ & This paper \\
\hline Menrva & $425 \pm 25$ & $490(+110 /-120)$ & SARTopo & N/A & N/A & Neish et al. (2013) \\
\hline
\end{tabular}

$1108{ }^{\mathrm{a}}$ Ganymede crater depths from Table 4 in Bray et al. (2012).

$1109{ }^{\mathrm{b}}$ Assumed to have the same depth as a $\mathrm{D}=100 \mathrm{~km}$ crater.

$1110{ }^{\mathrm{c}}$ Ganymede crater depths from Figure 2b in Schenk (2002).

\section{1}

1112 


\section{Figures}

1114

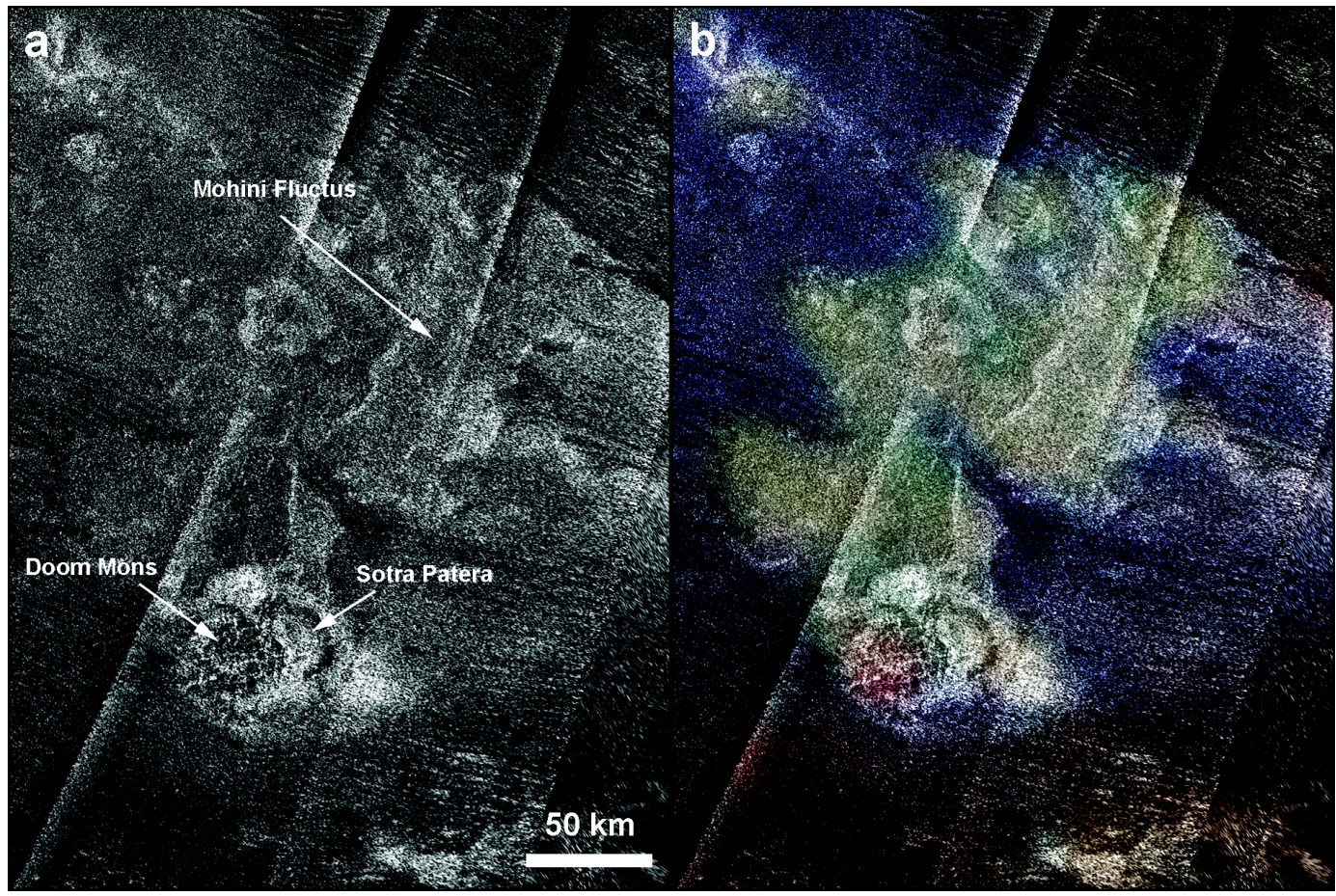

1116 FIG. 1. (a) Cassini RADAR image of Sotra Facula (centered near $13^{\circ} \mathrm{S}, 40^{\circ} \mathrm{E}$ ).

1117 Sotra Patera (a $1700 \mathrm{~m}$ deep pit), Doom Mons (a $1450 \mathrm{~m}$ high mountain), and

1118 Mohini Fluctus (flow-like features tens of meters high) are labeled. (b) Cassini

1119 VIMS image of Sotra Facula, overlaid on the Cassini RADAR image (R: average

1120 over 4.90 to $5.07 \mu \mathrm{m}, \mathrm{G}: 2.02 \mu \mathrm{m}, \mathrm{B}: 1.28 \mu \mathrm{m})$. The dune fields are 'brown' in

1121 colour and 'blue' regions may be enriched in water ice. The 'yellowish-green'

1122 regions have an unknown composition, but may be a combination of water ice and

1123 organic molecules (Neish et al., 2015).

1124 

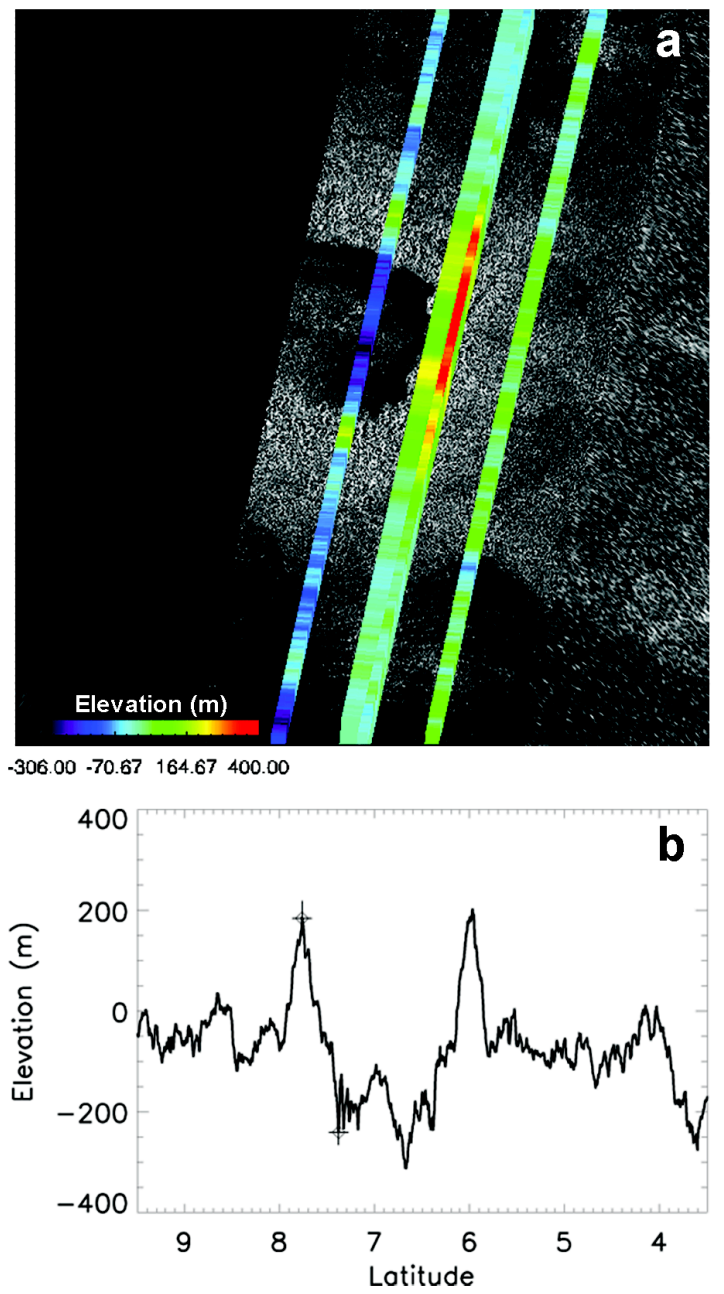

1126 FIG. 2. (a) SARTopo profiles overlain on a Cassini RADAR image of Selk crater.

1127 The colours refer to the relative height at any point. North is up, and the image

1128 covers the range $3.5-9.5^{\circ} \mathrm{N}, 196-202^{\circ} \mathrm{W}$. (b) The westernmost SARTopo

1129 profile from (a). Crosses indicate the points used to determine the depth of the

1130 northern half of the crater, $\mathrm{d}_{1}$. Similar depth measurements were made in the

1131 southern half of the crater. 

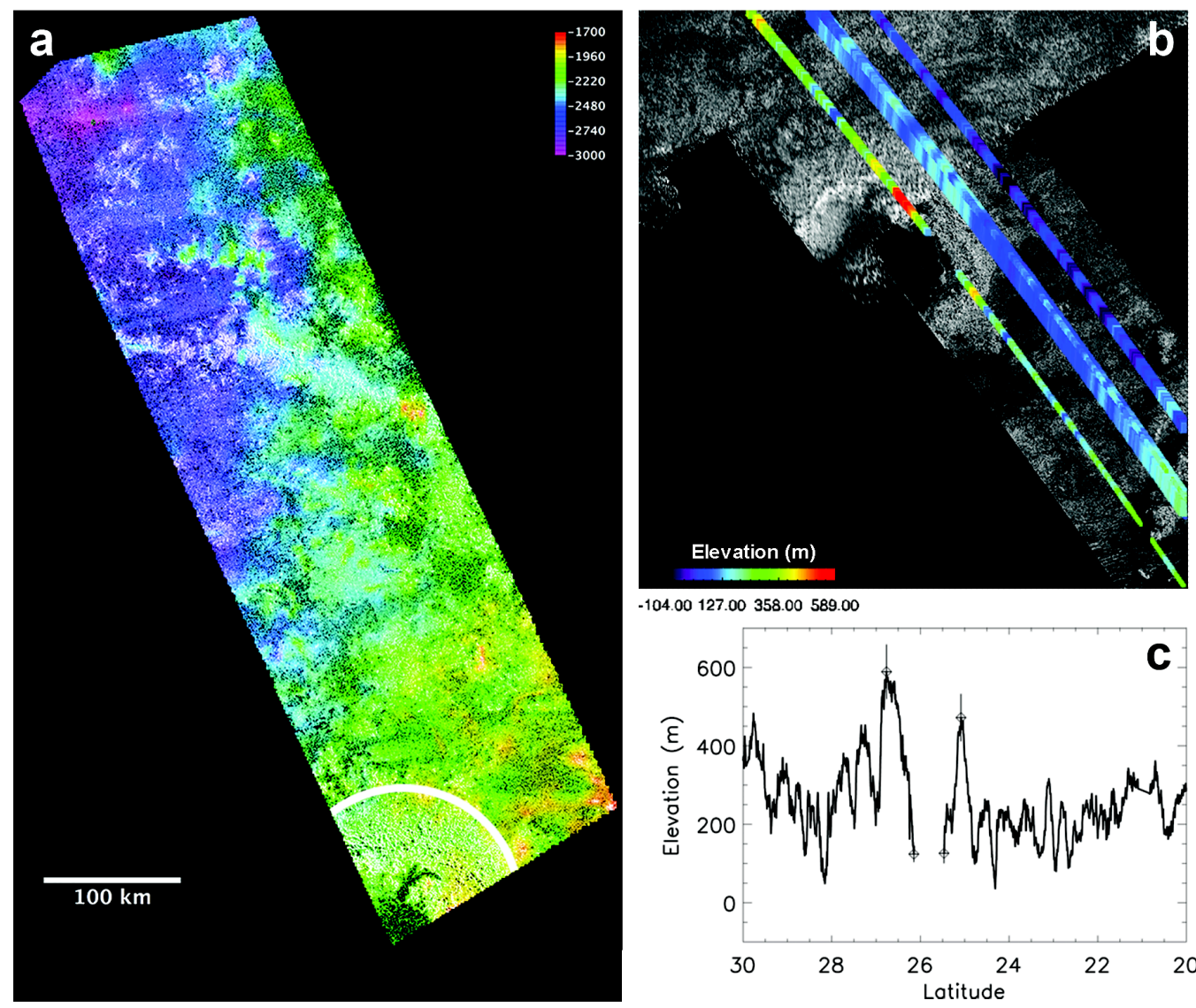

$-104.00127 .00358 .00589 .00$

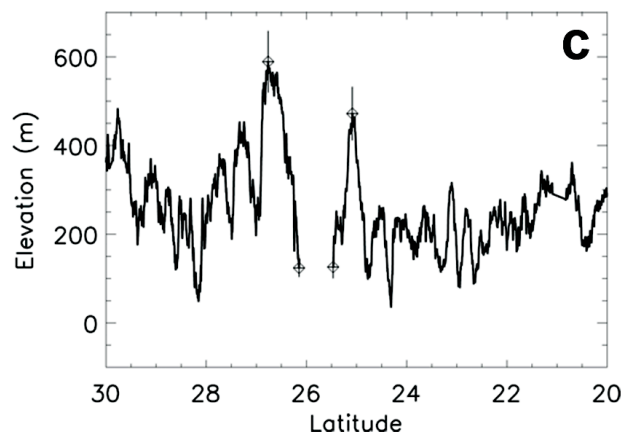

1133 FIG. 3. (a) Stereo topography of Forseti crater in the overlapping region of the

1134 T23 and T84 passes, overlain on a Cassini RADAR image. The crater is outlined

1135 at bottom left. (b) SARTopo profiles overlaid on a Cassini RADAR image of

1136 Forseti crater. The colours refer to the relative height at any point. North is up,

1137 and the image covers the range $20-30^{\circ} \mathrm{N}, 5-15^{\circ} \mathrm{W}$. (c) The westernmost

1138 SARTopo profile from (a). Crosses indicate the points used to determine the

1139 minimum depth of the crater.

1140 

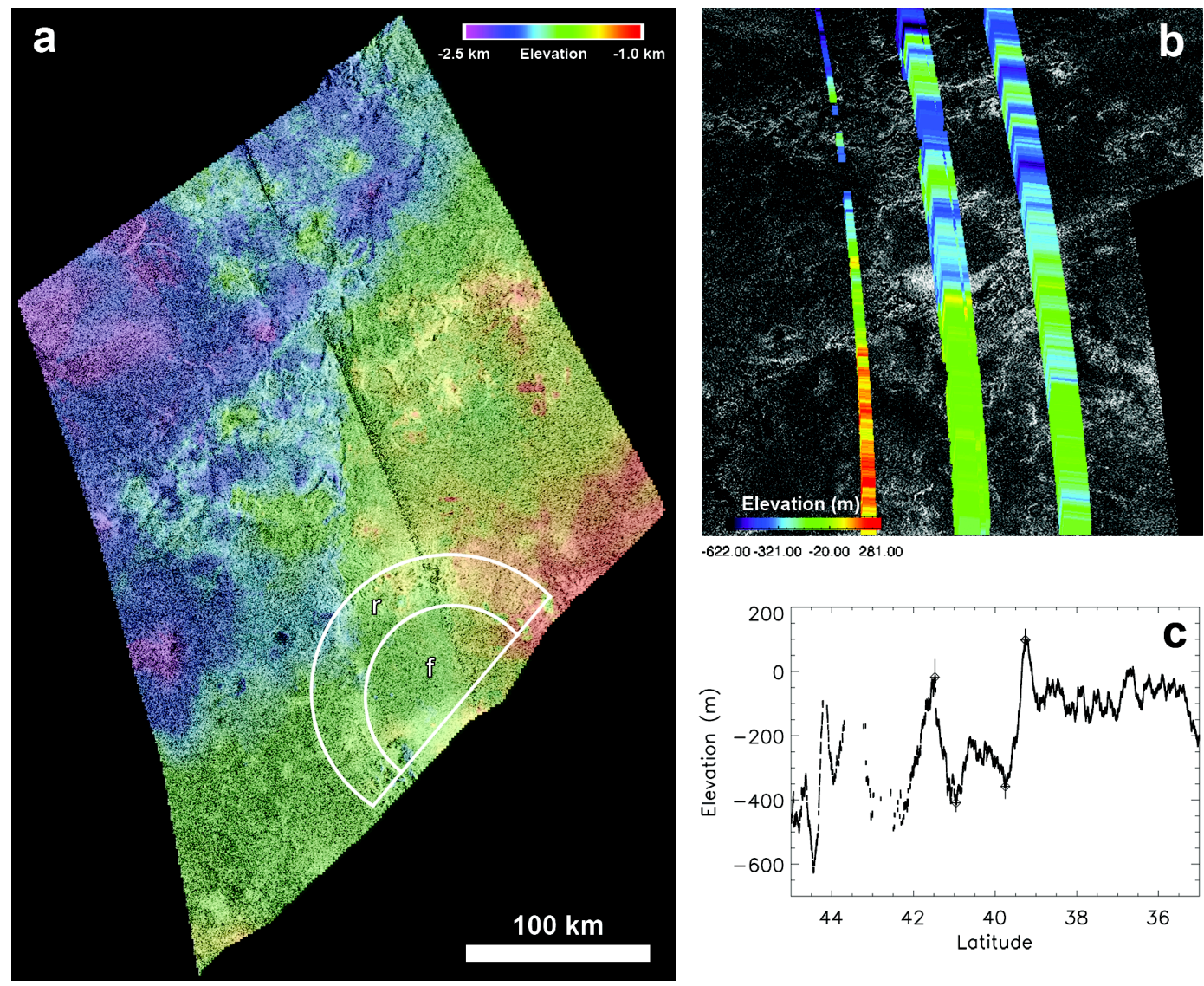

$-622.00-321.00-20.00281 .00$

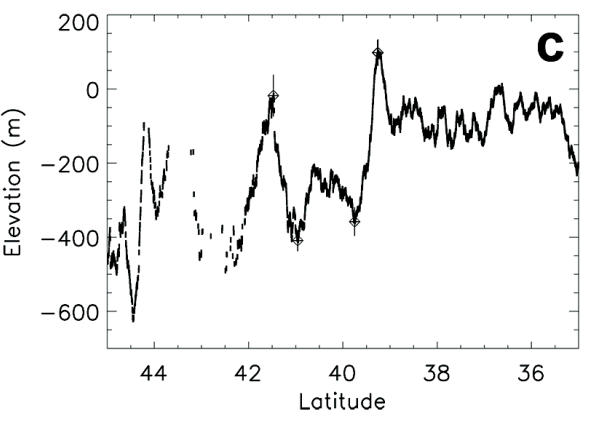

1142 FIG. 4. (a) Stereo topography of Hano crater in the overlapping region of the T16

1143 and T84 passes, overlain on a Cassini RADAR image. The regions of Hano crater

1144 used to estimate the floor elevation (f) and rim elevation (r) are outlined at the

1145 bottom. (b) SARTopo profiles overlaid on a Cassini RADAR image of Hano

1146 crater. The colours refer to the relative height at any point. North is up, and the

1147 image covers the range $35-45^{\circ} \mathrm{N}, 340-350^{\circ} \mathrm{W}$. (c) The center SARTopo profile

1148 from (a). Crosses indicate the points used to determine the depth of the crater. 


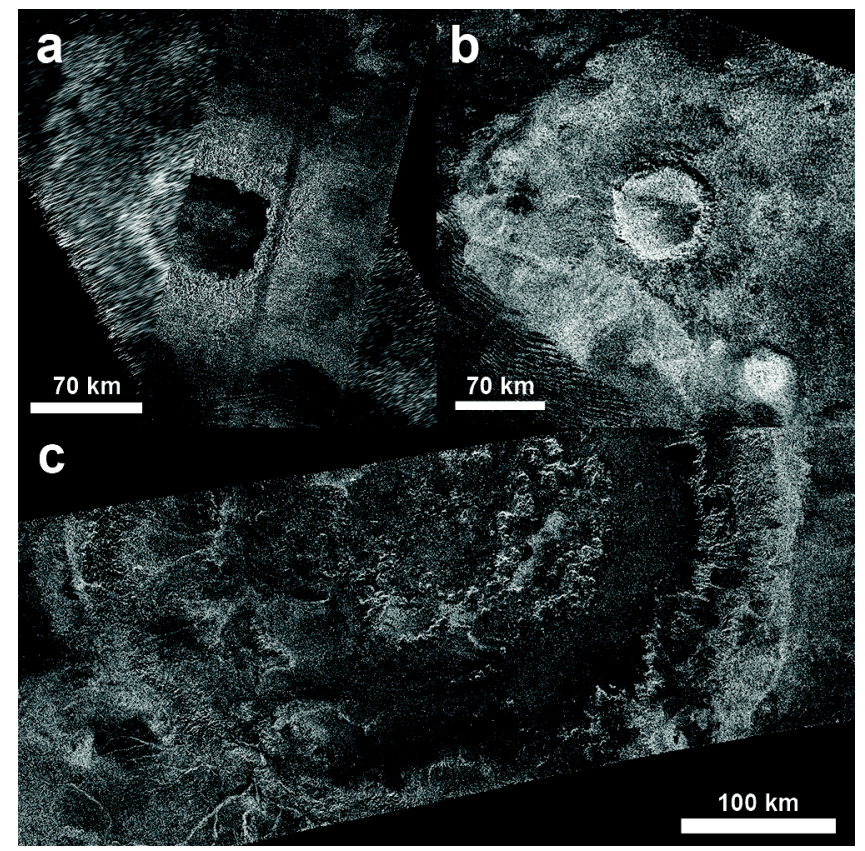

1152 FIG. 5. These three large, relatively unmodified impact craters on Titan would be

1153 the best locations to identify biological molecules on its surface: (a) The $79 \pm 7$

$1154 \mathrm{~km}$ diameter Selk $\left(7^{\circ} \mathrm{N}, 198^{\circ} \mathrm{W}\right),\left(\right.$ b) the $82 \pm 2 \mathrm{~km}$ diameter Sinlap $\left(11^{\circ} \mathrm{N}\right.$,

$\left.115516^{\circ} \mathrm{W}\right),(\mathrm{b})$ and (c) the $425 \pm 25 \mathrm{~km}$ diameter Menrva $\left(20^{\circ} \mathrm{N}, 87^{\circ} \mathrm{W}\right)$.

1156 

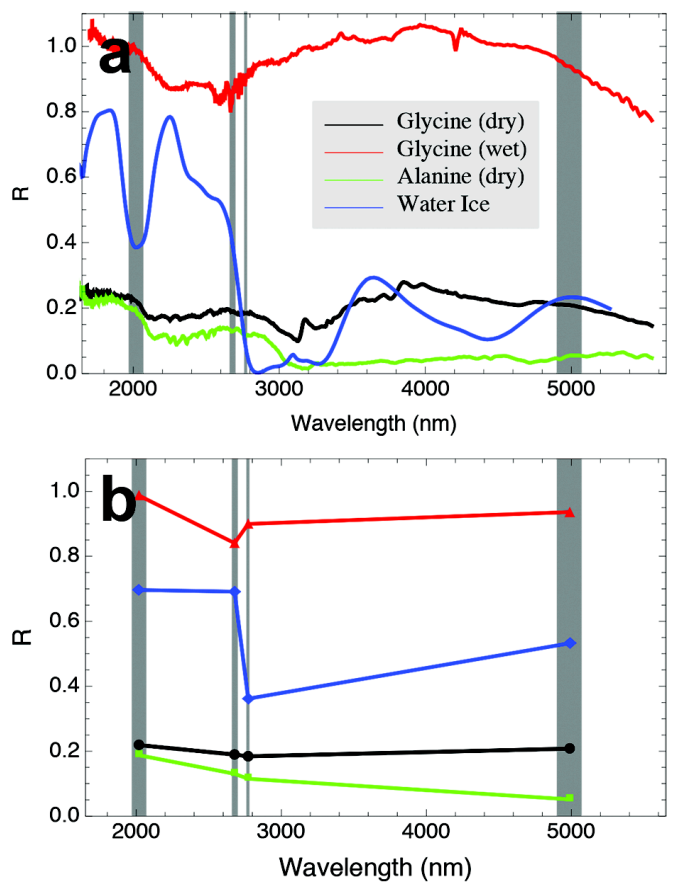

1158 FIG. 6. (a) Reflectance spectrum of powdered glycine (black), powdered alanine

1159 (green), pure water ice (blue), and glycine dissolved in water, frozen, and later

1160 warmed and desiccated under vacuum (red). Spectra of the amino acids have been

1161 obtained at both $100 \mathrm{~K}$ and room temperature, and they are identical for these

1162 materials. Shown in grey are the spectral windows through which VIMS can

1163 observe surface features on Titan. (Note that the 3.1- $\mu \mathrm{m}$ feature in the spectrum of

1164 dry glycine is due to water-ice build-up in the cryogenic infrared detector.) (b)

1165 Spectra of water ice (blue), “dry" glycine (black), “dry" alanine (green), and

1166 "wet" glycine (red) sampled in the four long-wavelength Titan atmospheric

1167 windows. The water-ice spectrum has been shifted vertically by 0.3 for ease of 1168 viewing. 


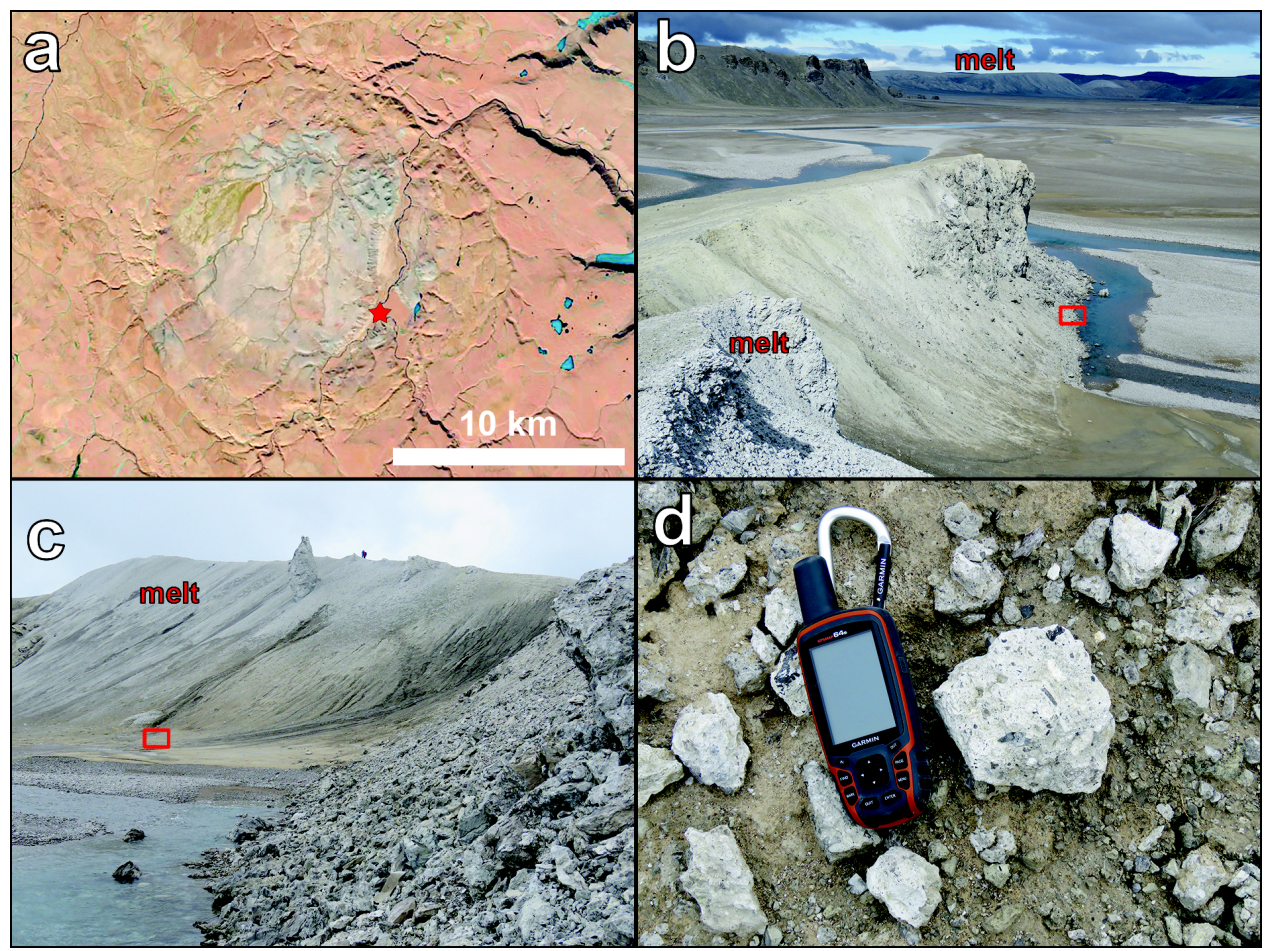

1170 FIG. 7. (a) Landsat-8 Operational Land Imager (OLI) natural colour image of

1171 Haughton crater $\left(75.4^{\circ} \mathrm{N}, 89.7^{\circ} \mathrm{W}\right)$ on Devon Island, Nunavut, Canada. The star

1172 indicates the location of (b). North is up. (b) Lighter toned impact melt has been

1173 exposed by the erosion of the impact crater interior by the Haughton River. View

1174 is to the north. The box indicates the location where the author photographed

1175 image (c). (c) Mass wasting and fluvial erosion brings samples of impact melt

1176 breccia into the smooth river valley bottom. View is to the south, and a person is

1177 visible on the ridgeline for scale. The box indicates the location where the author

1178 photographed image (d). (d) If craters on Titan are similar in morphology to

1179 Haughton, samples such as this $\sim 10$-cm cobble of impact melt breccia would be

1180 safely accessible by a lander on the flat floor of a river valley. 